Chinese soft power and its effects on Arab countries: The Arabian Gulf as a model

\author{
Widad Hammad Mukhlif \\ Werty.2000@yahoo.com \\ College of Education for Human Sciences / Anbar University \\ prof .Dr. Hussein Ali Abdul-Rawi \\ ed.hussein.ali@uoanbar.edu.iq \\ College of Education for Human Sciences / Anbar University \\ prof .Dr . AAYAD ABDULRIDHA ABDAL \\ aayad.abdal@ircoedu.uobaghdad.edu.iq \\ College of Education Ibn Al-Rushd for Human Sciences / University \\ of Baghdad
}

DOI: $\underline{10.31973 / a j . v 2 i 136.1281}$

\begin{abstract}
This research deals with the study of Chinese soft power and its effects on one of the most important regions in the world, which is the Middle East region, and the Arab Gulf region was a model for research, and it was found that through soft power, a country can penetrate other countries through a variety of tools without resorting to hard power. . Three components of soft power were found: Culture, political values and foreign policy, as soft power does not mean concern for national interests only and ignoring the interests of others. By getting to know the components of Chinese soft power that have been identified in research and its continuous growth, China has been able to build its soft power in areas that include (components Political, economic, social and technological). It has played the tools of Chinese soft power: Culture, foreign policy and political values have an important role in establishing the principle of peace and international and regional cooperation, and through China's pursuit, in its foreign policy, to create a safe environment for economic growth, avoiding conflicts and disputes, and opening up to the world. The study found that there are effects of Chinese soft power in the Arab Gulf region, especially since the Chinese economic rise has made the Arab Gulf states the first supplier of oil, and that China's investments in the Arab Gulf region in various fields have contributed to the impact of its economic tools in the region, and on the other hand. Chinese exports, including the military industries, increased to the Arab Gulf states, and they occupied advanced ranks in the import table. In addition, China seeks to find an important role for it in the future in protecting international shipping lines in the region to protect its growing economic interests. Politically, it has been shown that China has always emphasized its non-interference in the affairs of the countries of the region and sought to maintain its stability, which had a major role in developing political relations between the Arab Gulf states and China.
\end{abstract}

Key words: soft power, culture, political values, foreign policy. 


\section{القوة الناعمة الصينية وآثارها على الدول العربية}

\section{(الخليج العربي نموذجا)}

أ.د. حسين علي عبد الراوي

كلية التربية للعوم الإنسانية / جامعة الانبار

ed.hussein.ali@uoanbar.edu.iq
م.م. وداد حماد مخلف

كلية التربية للعلوم الإنسانية / جامعة الانبار

Werty.2000@yahoo.com

أ.د. أعياد عبد الرضا عبدال

كلية التربية ابن الرشد للعلوم الإنسانية / جامعة بغداد الداد

aayad.abdal@ircoedu.uobaghdad.edu.iq

(مُلَخََّصُ البَحثث)

تتاول هذا البحث دراسة القوة الناعمة الصينية واثارها على واحدة من اهم المناطق في

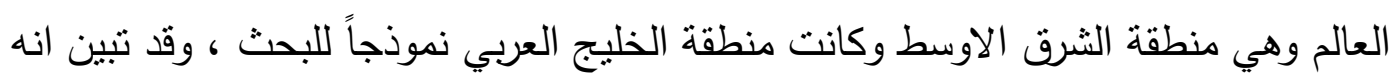

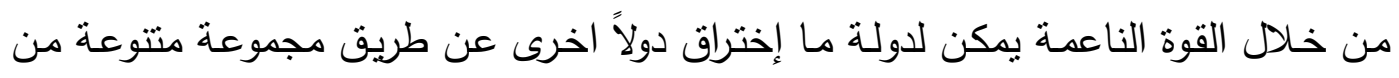

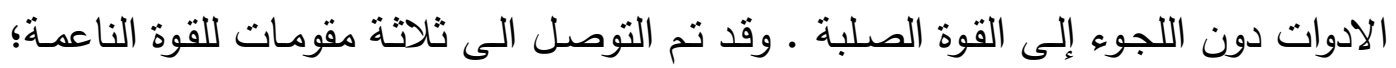

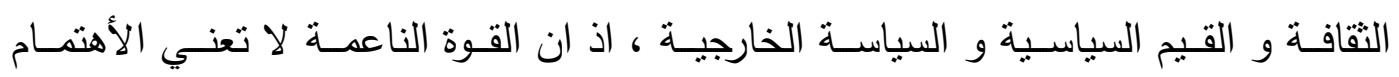

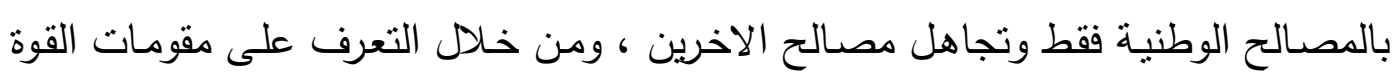

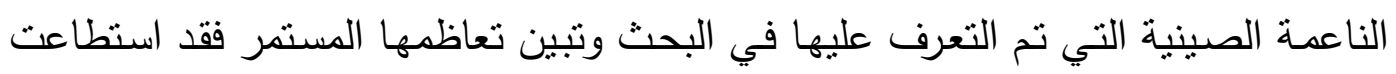
الصين بنـاء قوتها الناعمـة في مجـالات شـلت (مقومـات سياسية واقتصـادية واجتماعيـة

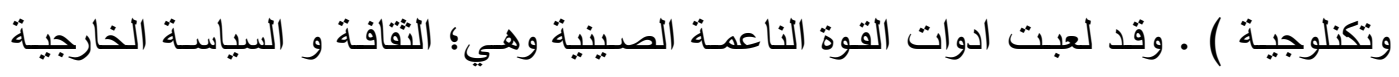

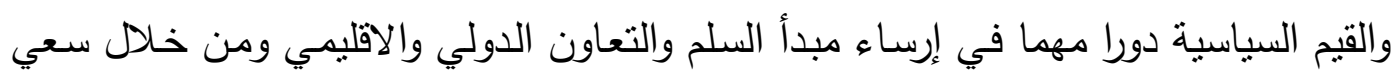

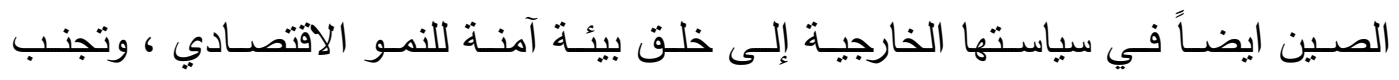

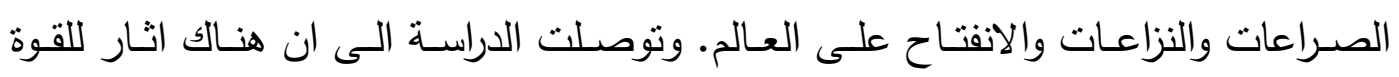

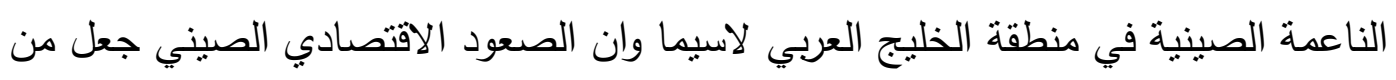

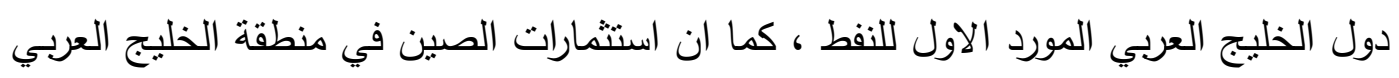

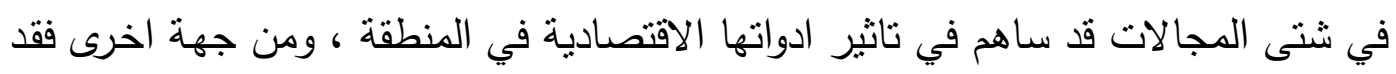

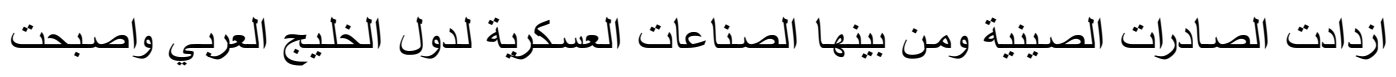

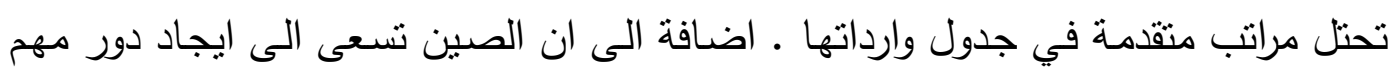

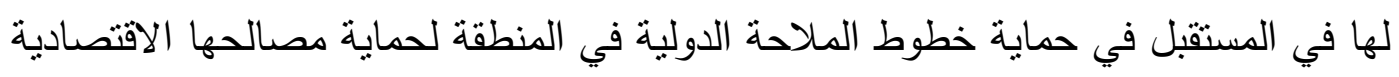

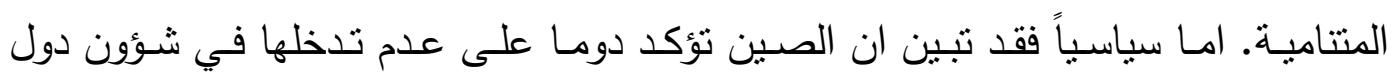


المنطقة وسعت الى المحافظة على استقرارها مـا كان لـه دور رئيسي في تتمية العلاقات

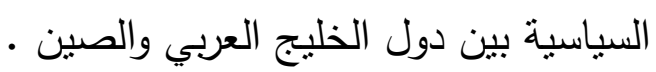
الكلمات المفتاحية: القوة الناعمة ، الثقافة،القيم العياسية، السياسة الخارجية .

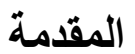

اعتبرت القوة العسكرية على مر العصور خيار الدولة الاول بالنسبة لبقية الخيارات

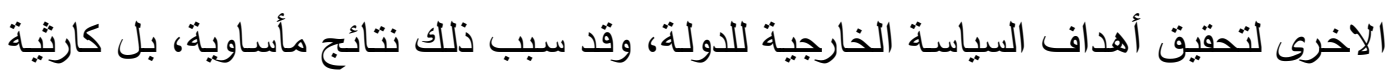

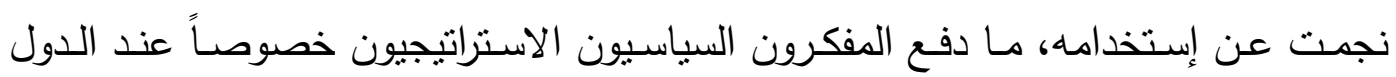
العظمى للبحث عن بدائل أخرى تُجنب البشرية الدمار والخراب الذي بتسبب من جراء إستخدام القوة العسكرية في حل اثكالاتها. حتى ان الدول ساعدت جاهدة لدعم الإفكار

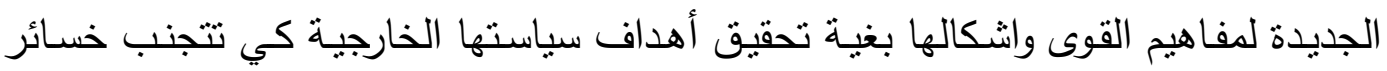

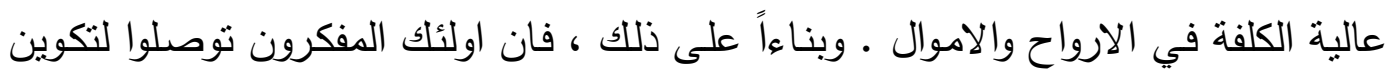

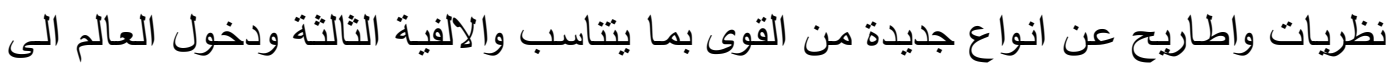

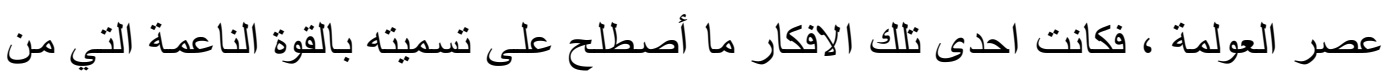

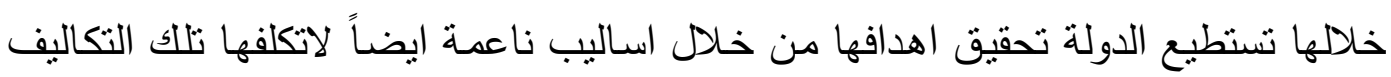

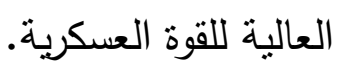
وفي ضوء ما تقدم، فقد ركز البحث على معالجة موضوع القوة الناعمة، والاتجاهات الفكريـة الداعيـة إليها التي تحث الدول على توظيفها كخيـار بديل عن قوتها العسكرية (الصلبة) وخصوصا بعد ما تعرضت له من إنتقادات، أو خسائر في حروب خاضتها دول

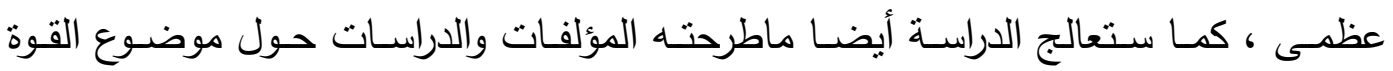

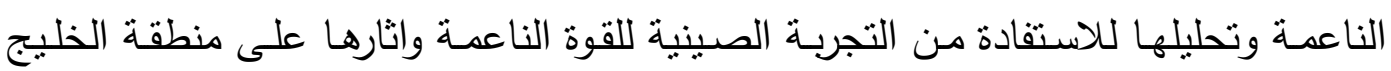

تكمن أهمية البحث في كونه يتطرق لمفهوم حديث نسبياً وهو القوة الناعمة والذي يحتل

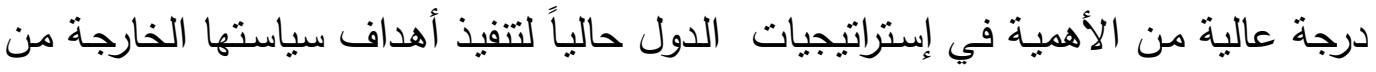

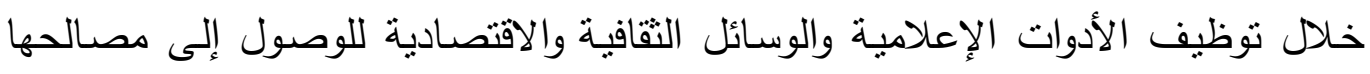

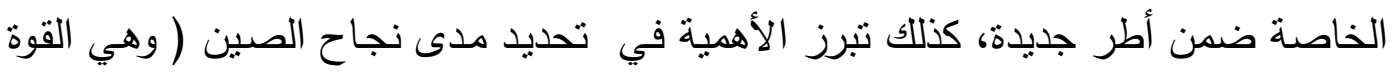

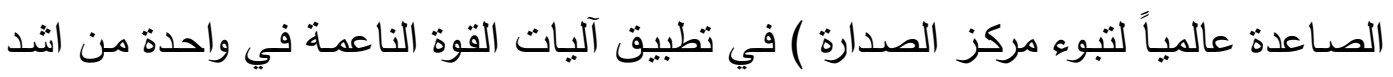

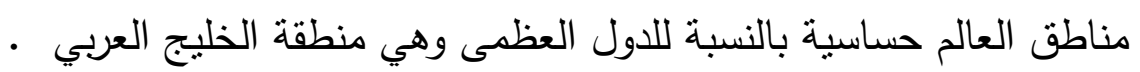


إثكالية الاراسة

تكمن انكالية الدراسة في البحث في قدرة الصين في منافسة القوى العظمى في بسط

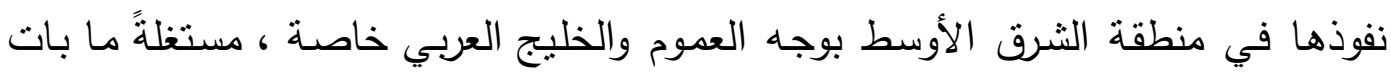
يعرف بالقوة الناعمة، إذ ثبت إلى حد كبير عدم فاعلية القوة الصلبة في تحقيق أهداف الدول العظمى في الدنطقة، الأمر الذي أدى إلى التحول نحو القوة الناعمة التي أثنتت أنها لا تقل أهمية وفاعلية عن القوة الصلبة ويمكن صباغة ذلك في التساؤلات الآتية : ا. كيف استطاعت الصين استغلال أدوات القوة الناعمة لديها من تحقيق استراتيجيتها لإحداث تغييرات بنيوية في منطقة الخليج العربي •

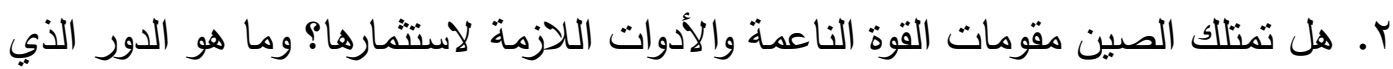
ممكن ان تؤديه القوة الناعمة الصينية في مواكبة التطورات الحاصلة في منطقة الثرق الأوسط والخليج العربي خصوصاً.

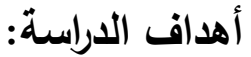

يمكن تحديد اهداف الدراسة من خلال مايلى: 1. التعرف على مقومات القوة الناعمة الصينية وادواتها. r. التعرف على الأهمية الجيواستراتيجية لدنطقة الخليج العبي والاهتمام الدولي بها.

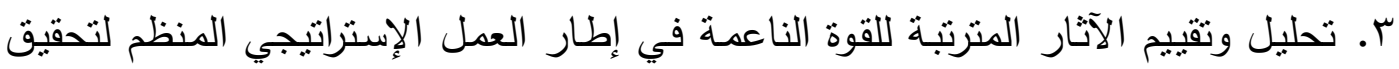
أهداف السياسة الخارجية الصينية في منطقة الخليج العربي.

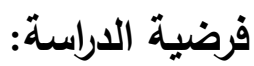

إن الفرضية التي تسعى الدراسة إلى إثباتها هي:

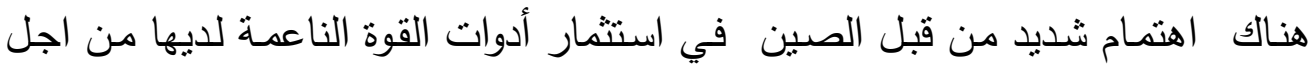
الاحتفاظ بدور منقدم وفاعل في الثرق الأوسط وعلى وجه الخصوص منطقة الخليج العربي منهجية الدراسة :

تم تاطير الجزء النظري من الدراسـة بالاستعانة بمجموعة المصـادر والمراجع العربية والاجنبية المتوفرة في المكتبات الاكاديمية وشبكات الانترنت مستعينين بالمنهج الوصفي في ذللك ، ثم محاولة استقراء بعض النتائج من خلال تحليل اقوال وتصريحات مسؤولين وباحثين ومنظرين لاتمام الجزء العملي من البحث.

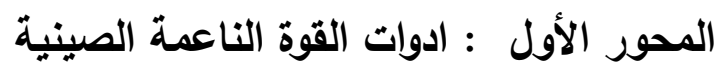
استطاعت الصين بناء قوتها الناعمة في مجالات (النقافة، والقيم السياسية، ونموذج الهيه التتمية والمؤسسات الدولية، والتتكيل الدولي والمغريات الاقتصادية) والتي يمكن ممارستها عبر ثلات قنوات دبلوماسية: الدبلوماسية الرسمية والاقتصادية والعامة Li\& Verner ) 
(75: Worm , 2010 ولقد اختلفت أدوات القوة الناعمة الصينية وتميزت عن باقي الدول بسبب خصوصيتها السياسية والاقتصادية والثقافية وكما يلي : أولاً : الثقافة بعد تبنـي الدولـة للقوة الناعمـة فقد سـاد الـرأب الفكري الان بـأن الثقافـة هـي المسورد

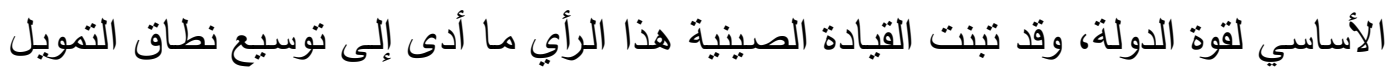

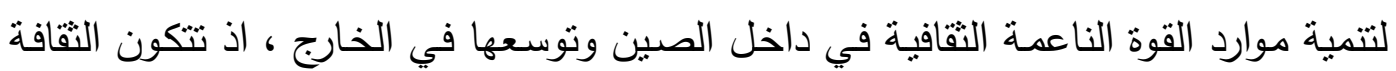

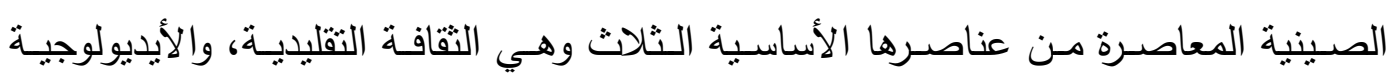

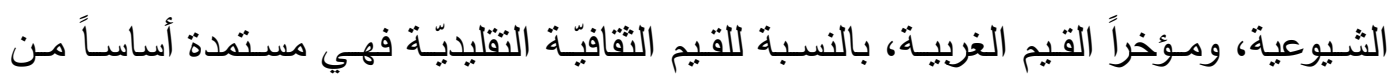
الكونفوشيوسية والطاويّة ثم البوذيّة، وتعتبر الكونفوشيوسية القاعدة الأساسية للتقليد الثقافي

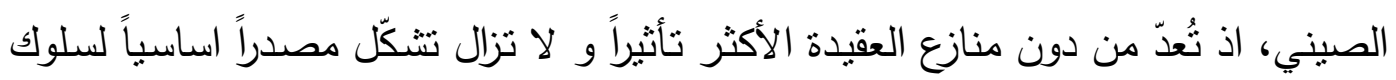

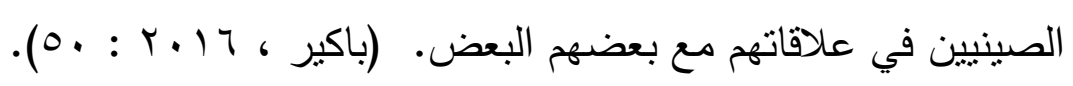

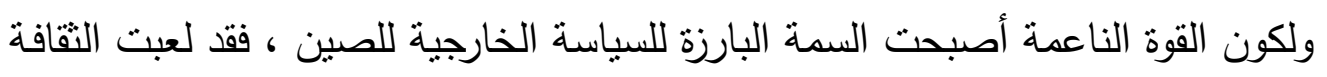

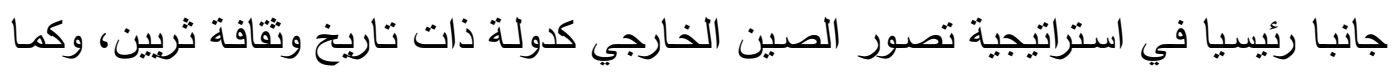

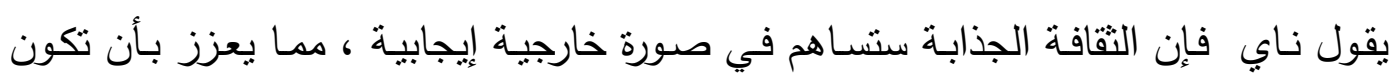

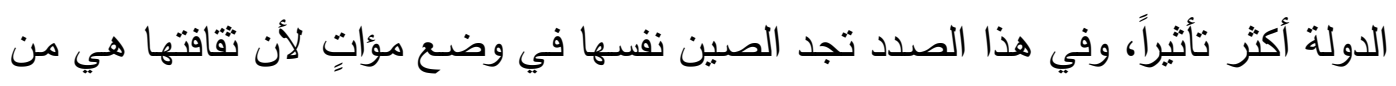

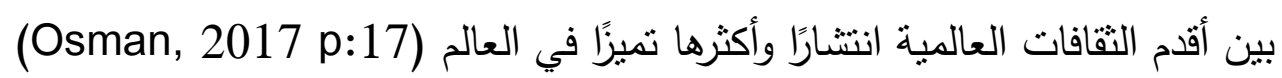

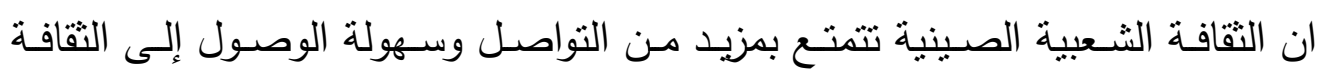
الرفيعة ، تمامًا مثل الأفلام وغيرها من أثكال الترفيه الجماعي ، ويمكن أن تتشر أفكارًا

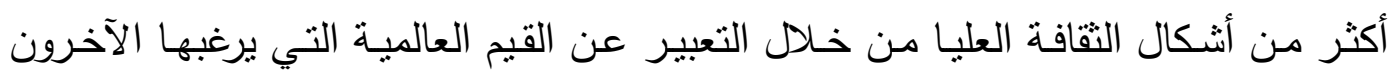

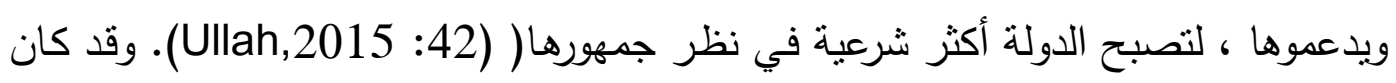

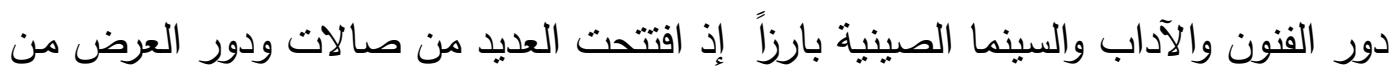

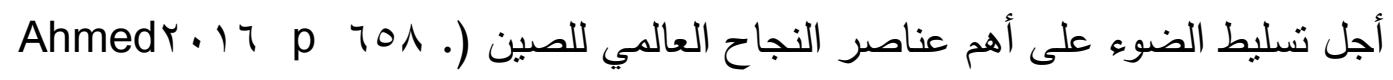

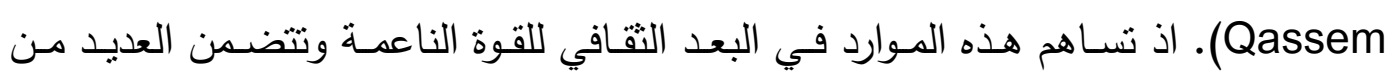

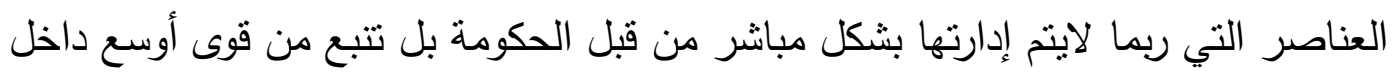

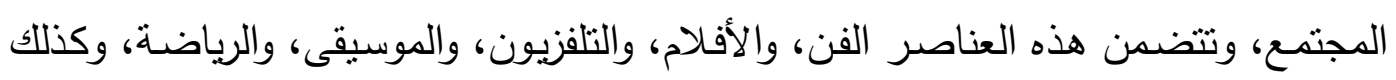

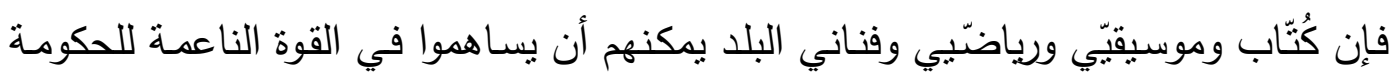

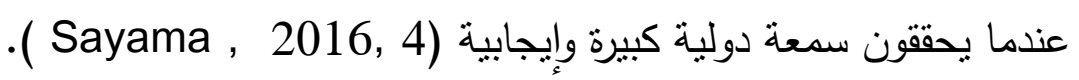
وكنتيجة للاستراتيجية النقافية فقد انتشرت عدد معاهد كونفوشيوس بسرية دوعة إلى أكثر من

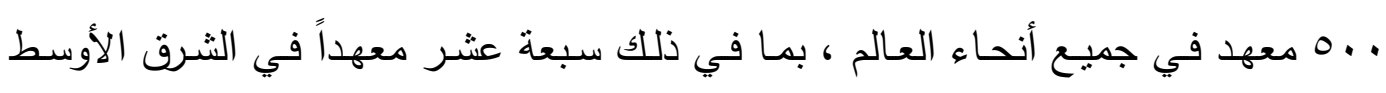
وخمس فصول كونفوشيوس ، وهي عبارة عن "صفوف دراسية" للتعلم الصيني داخل المعاهد 


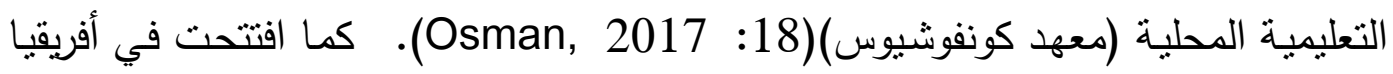

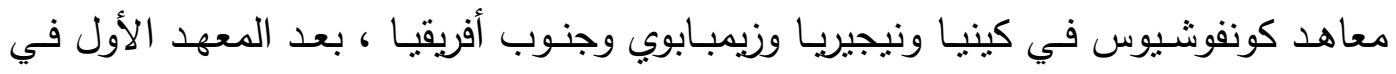

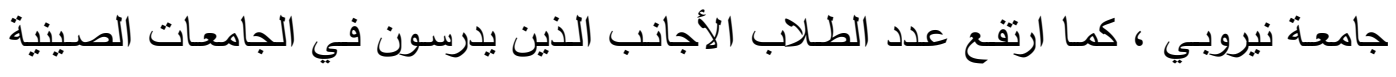

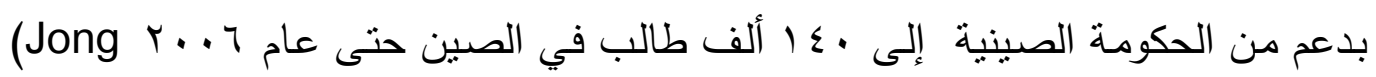

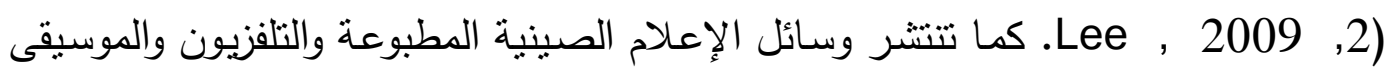

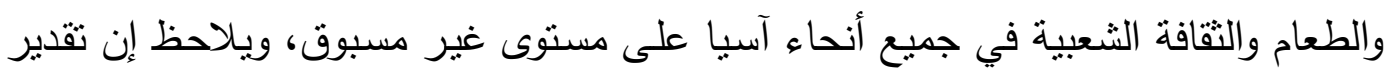

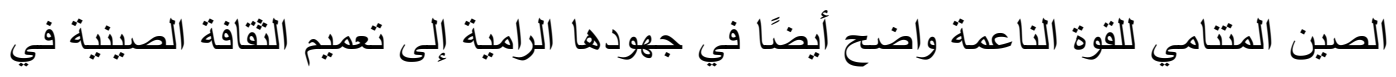

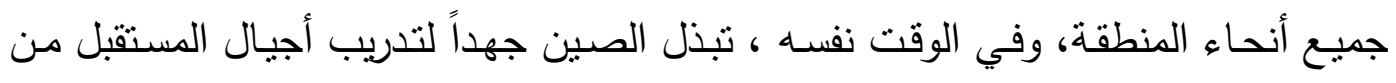

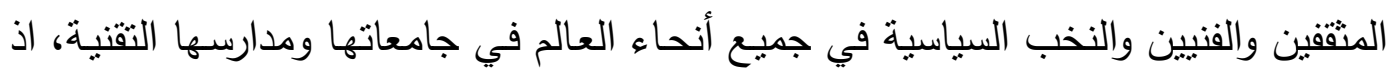

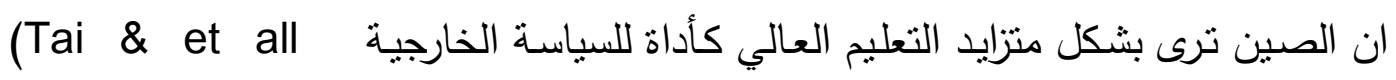
.2014:31)

ان الثقافة الصينية قد دخلت الآن في مرحلة ما يسمى بحلم الصين، لقد كان تحول

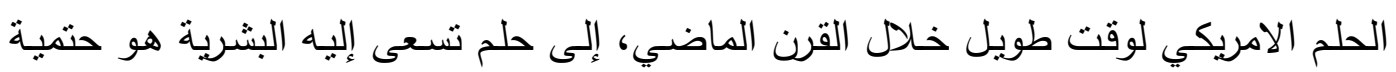

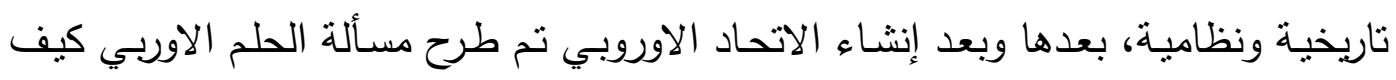
يمكن لأوربا تحقيق حلمها، وهنا كانت رغبة الاوربين في تحقيق حلمهم بطريقتهم، واستتاداً

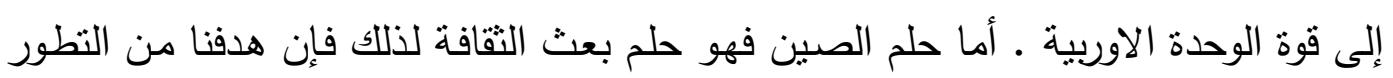

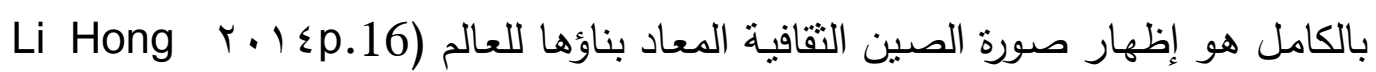
.(jie ثانياً : السياسة الخارجية لقد امتازت نظرة الصين إلى العلاقات الدولية بالتقليدية مركزةً على مبدأ السيادة للدولة

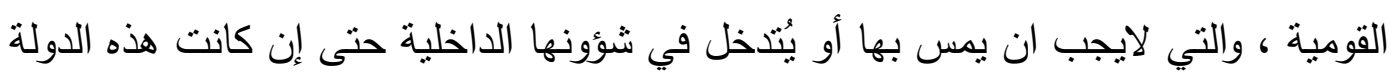

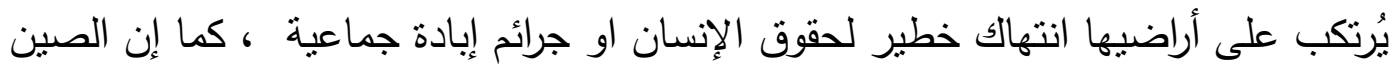

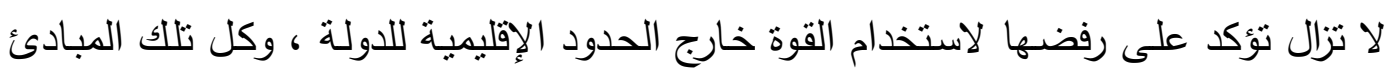

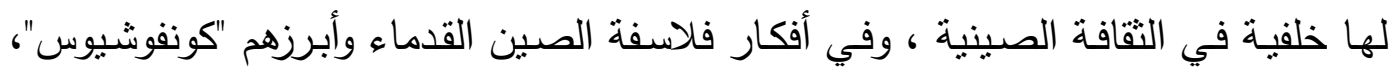

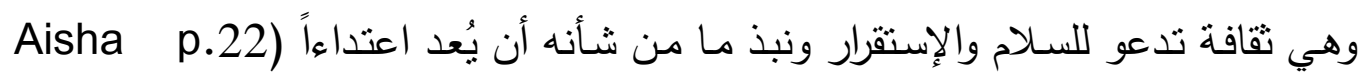

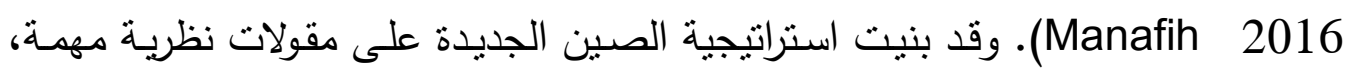
أبرزها( Al-Badrani ALI 2015 P.9 ) ( 1- إن صعود الصين قام على تعظيم الانتاج الاقتصادي ، خصوصـا في مجال المبادلات

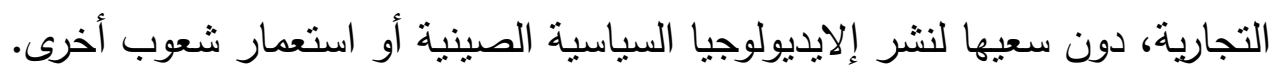


r-تعلن الصين باستمرار رفضها للحلول العسكرية في زمن العولمة، وتشابك المصالح بين

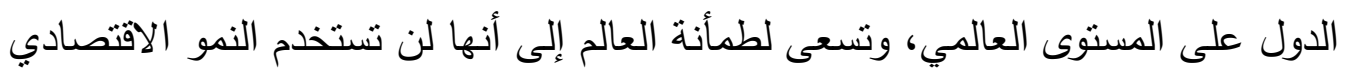
لتحقيق أهداف عسكرية توسعية والسيطرة على الدول الاخرى.

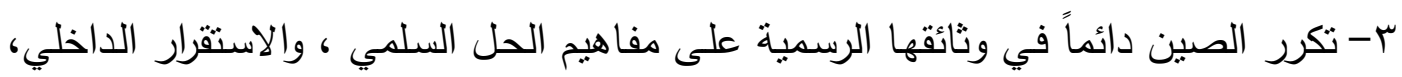

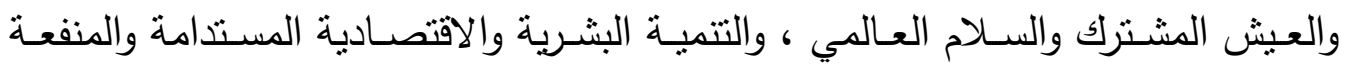

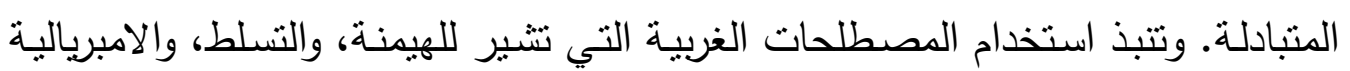
والاستعمار الجديد، وغيرها.

ع - تدعو الصين لبذل جهود دولية مشتركة لمواجهة تحديات العولمة في ظل أزمات عالمية

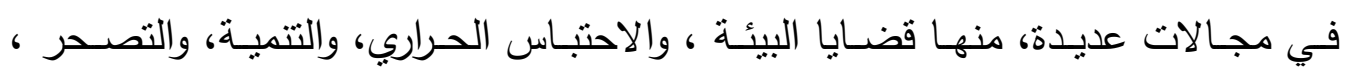
ونقص الغذاء، ومواجهة كوارث الطبيعة.

ه- لاتزال الصين تصنف نفسها دولة نامية كبيرة، لديها قدرات اقتصادية وعسكرية ضخمة تؤهلها لدور مركزي في النظام العالمي الجديد.

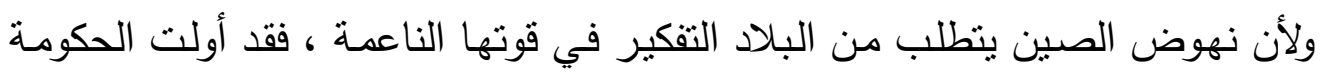

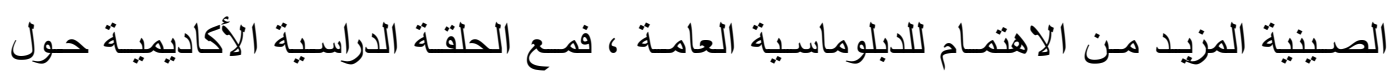

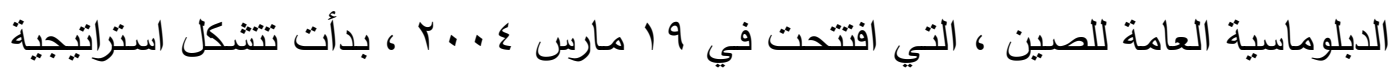

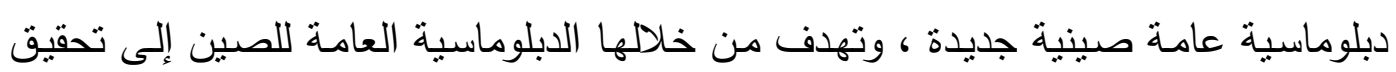

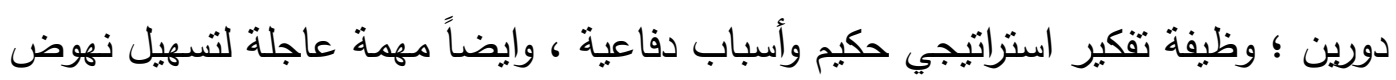

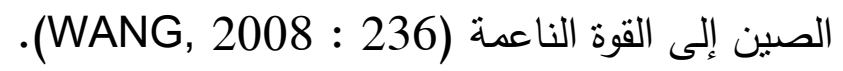

وقد اتبعت الصين باستمرار مبادئ التعايش السلمي وعدم التدخل في الثؤون الداخلية للأمة الأخرى التي تكافئ الصين بالصداقة والصداقة في العديد من البلدان. تدعو الصئ الصين الصني

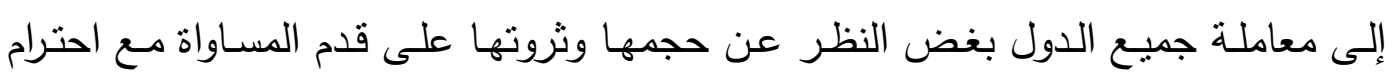

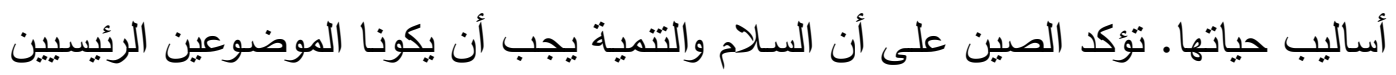

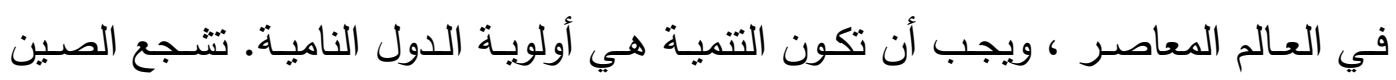

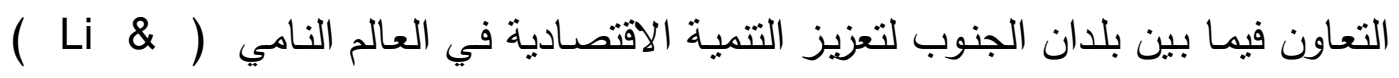
.Worm , 2010: 78

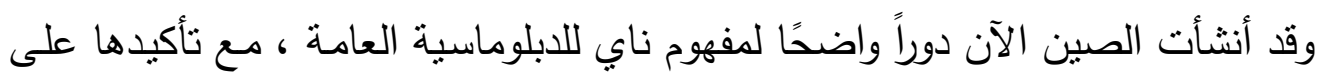

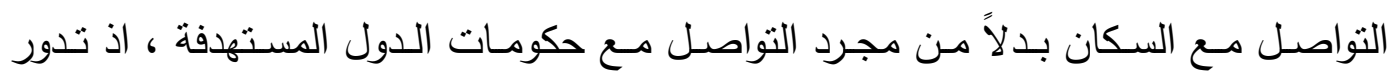

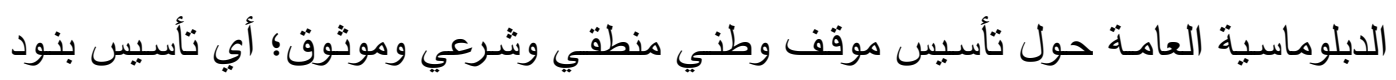

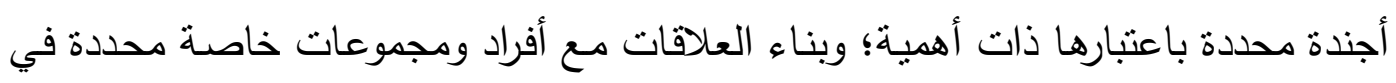

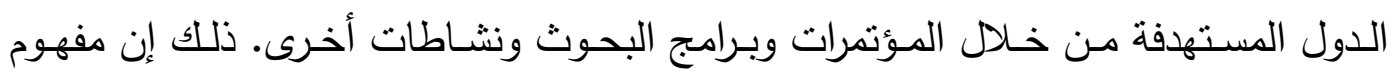


الصين للقوة الناعمة يتضمن التواصل بين المواقف الصينية والأراء، وترسيخ صورة دولية Sayama , ) جيدة للصين، وخلق بيئة دولية مواتية، والترويج لعالم مسالم ومتتاغم ومتعاون لئن . (2016, 11

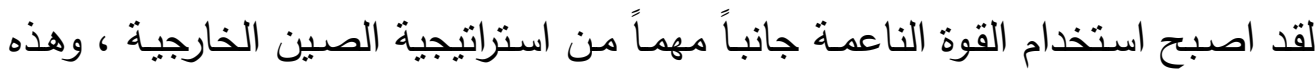

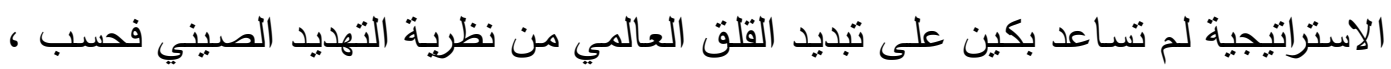

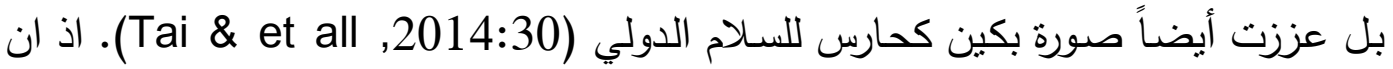
تبني استراتيجية القوة الناعمة في السياسة الخارجية خطوة ضرورية لإسقاط الثنكوك المحيطة بصعودها ، وقد تحقق استراتيجية القوة الناعمة هدفين هامين للصين: 1- تقليل تأثير نظرية التهديد الصيني وتحدياتها على الأمن القومي •

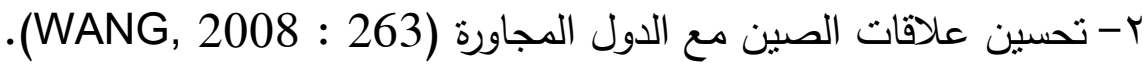
كمـا تقوم الصين بدبلوماسية متعددة الأطراف نشطة وطوعيـة منذ نسعينات القرن

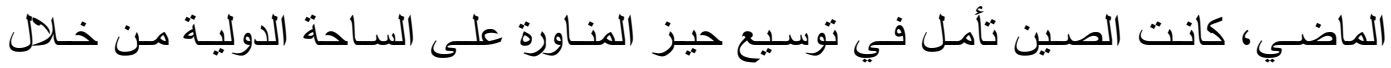

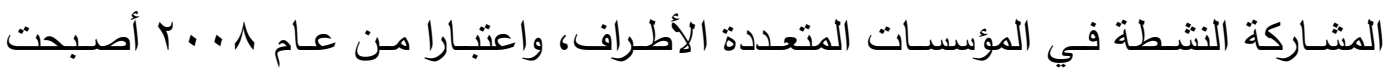

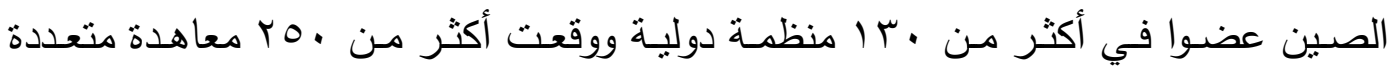
الأطراف ، وكانت مشاركة الصين في المنظمات الحكومية الدولية والمنظمات غير الحكومية

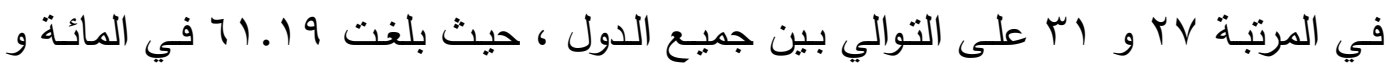

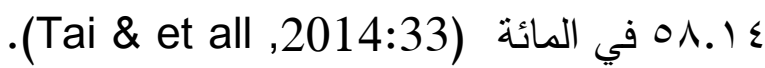
ثالثاً :القيم السياسية لم يعرف العالم حضارة حافظت على نقاء هويتها مثل الحضارة الصينية، وقد أثرت فيما حولها عبر دياناتها التي تضفى حالة من اليقظة لامتلاك المعرفة المباشرة للأشياء وحقيقة الكون. و الحضارة الصينية متجانسة، ومنصهرة في وحدة واحدة بحكم العزلة التي فرضتها

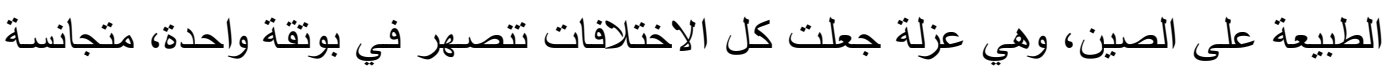
في شعب واحد. وبرغم أن الصين من أقدم الحضارات فإن ذاكرتها لاتزال حاضرة، ومؤثرة، وفعالة حنى الآن (Nafi Ibrahim 1999.P.6) ان حضارة الصين القديمة وقيمها الأخلاقية قد انعكست بشكل كبير على واقع الصين

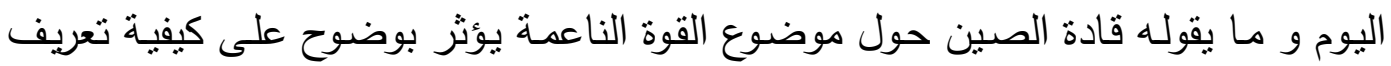

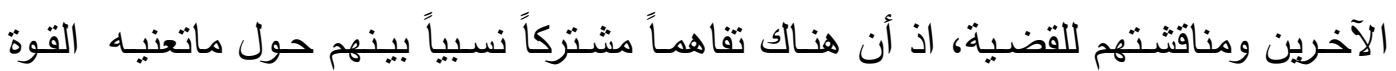
الناعمة ، و يُنظر إليها إلى حد كبير كمشروع لتدويل صوت الصين بحيث يخترق الوعي

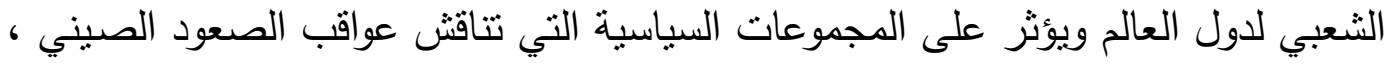

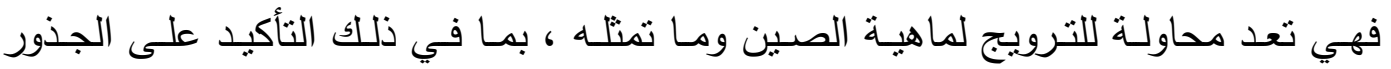


التاريخية للتفكير الحالي ، وتتشكيل الهوية والسياسة المصممة لتصحيح التصورات الخاطئة

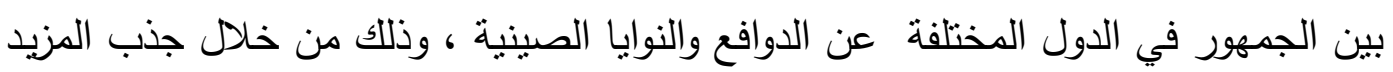

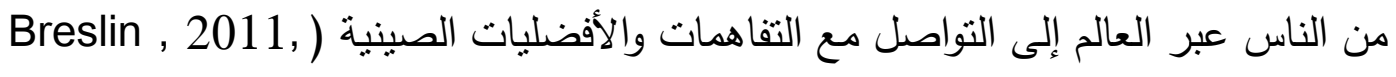
7). وبرغم مايوجه للصين من نقد بانها ليست معترف بها من حيث قيمها السياسية بشكل

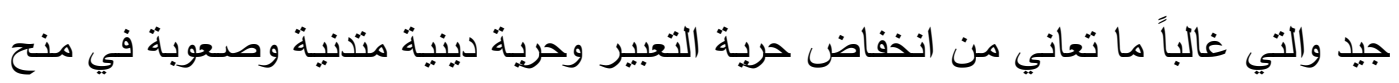

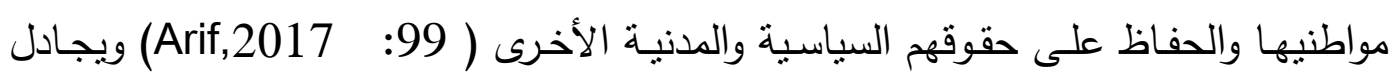

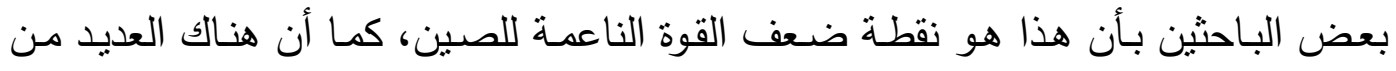

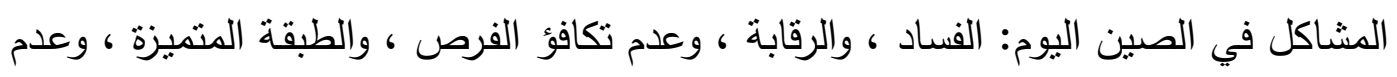

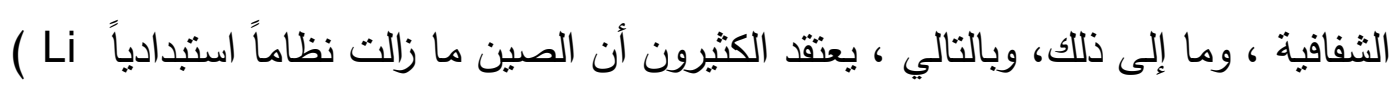

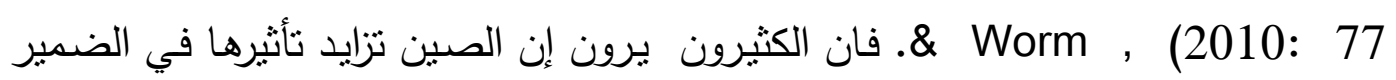

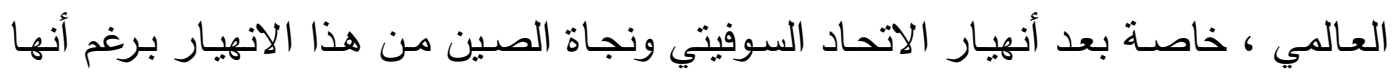

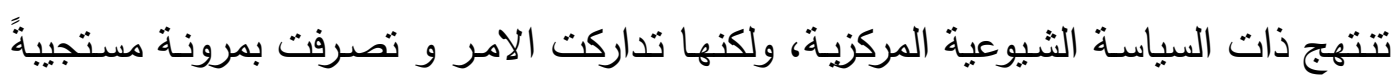

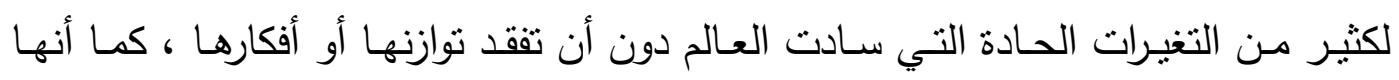

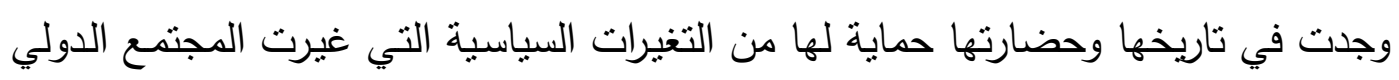

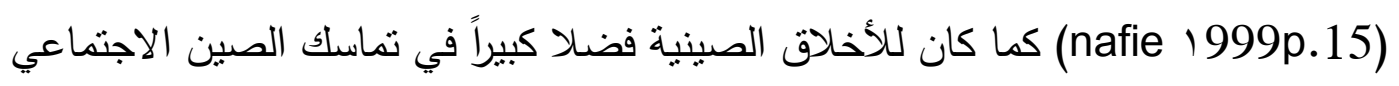

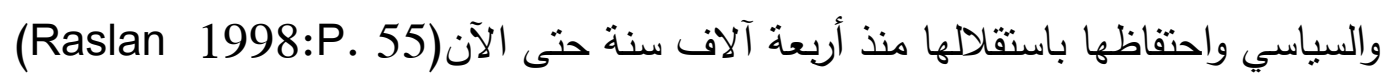

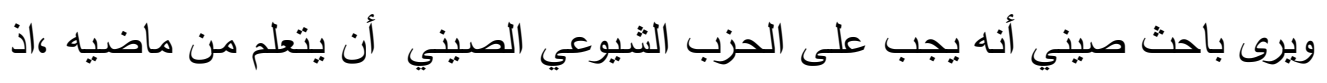

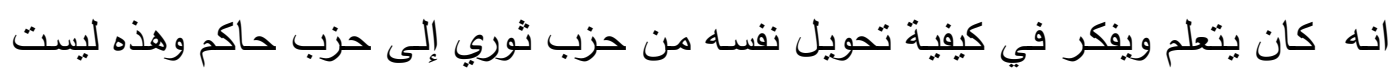

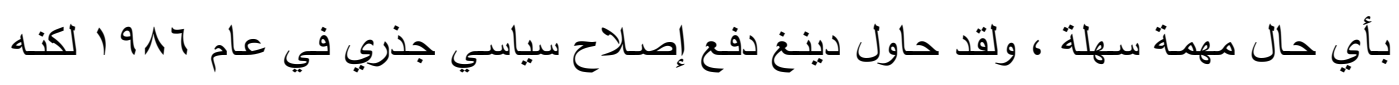

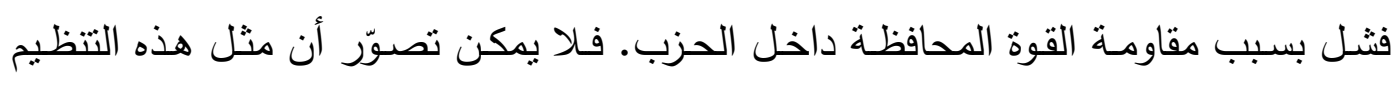

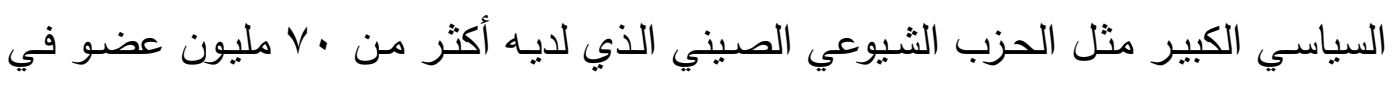

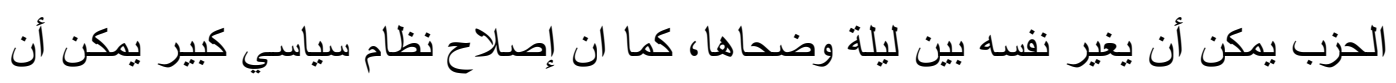

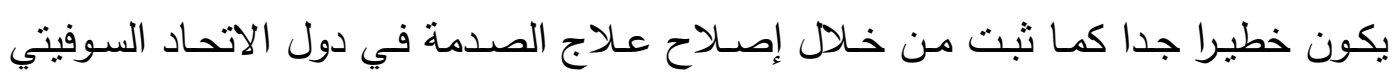

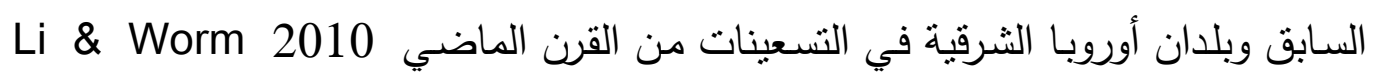

المحور الثاني:أثار القوة الناعمة الصينية في الدول العربية (الخليج العربي نموذجاً)

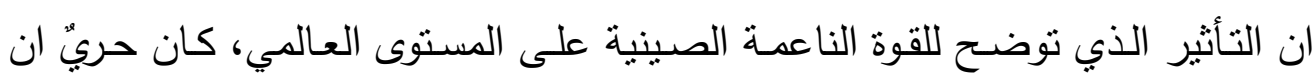

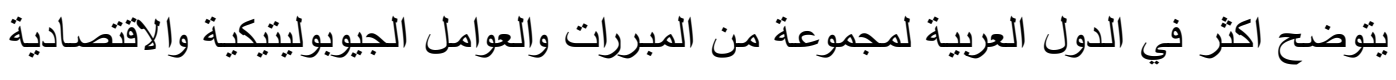

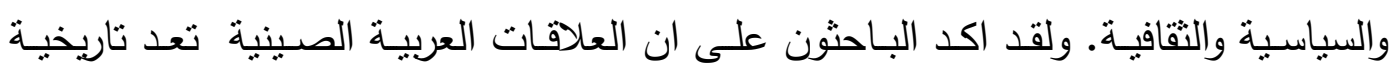

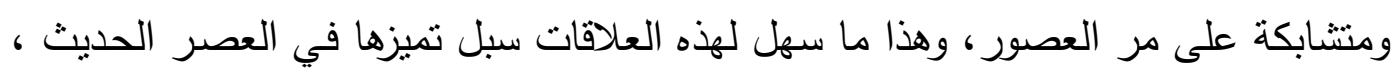


ولم يختلف العرب على علاقاتهم مع الصين ، فعلى الرغم من اختلاف الدول العربية فيما

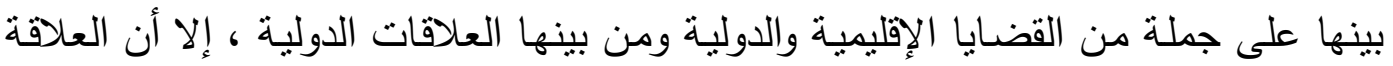

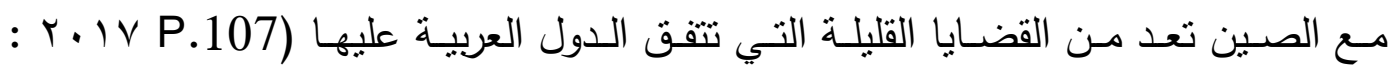
alhidad ). وعند التحدث عن الخليج العربي ففي الوقت الذي تراجعت او انعدمت فيهـ

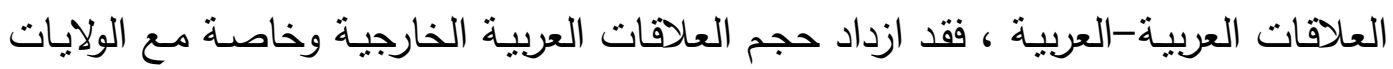

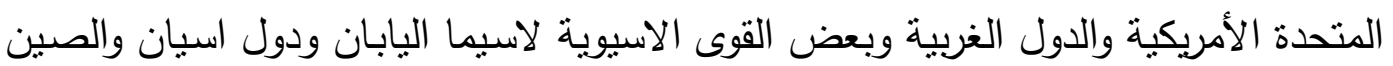

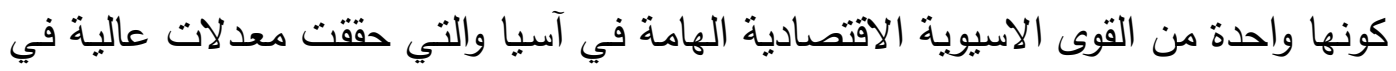

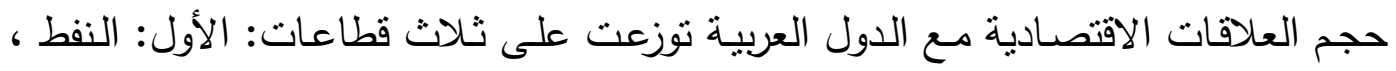

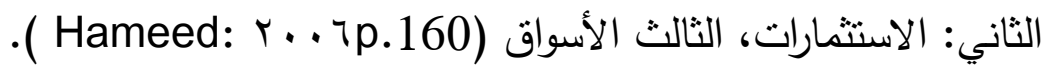

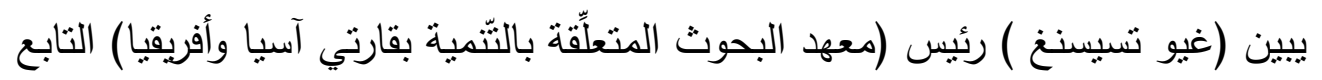

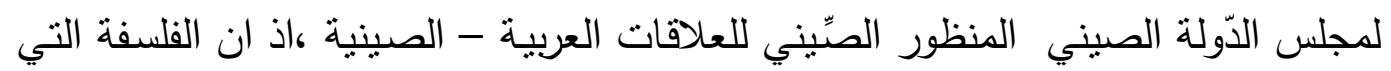
تقوم عليها السياسة الاقتصاديّة الصِّينية تجاه البلاد العربيّة تتمثل بالعمل على دعم التعاون

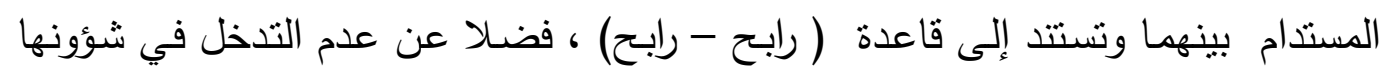
الدَّاخلية ، منلما تقوم به الولايات المتحدة الأمريكية في ما بخصُّ مساوماتها للاستثمار مقابل تدخلها المباثر وفرض رقابتها على ملفَّي الدّيمقراطية وحقوق الإنسان في البلدان العربية العبيّة

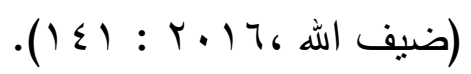

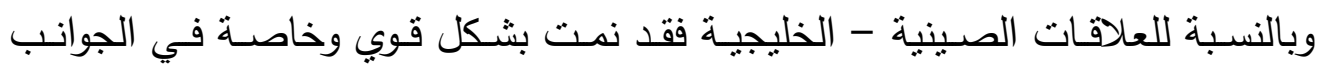

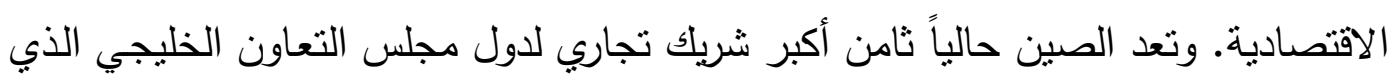

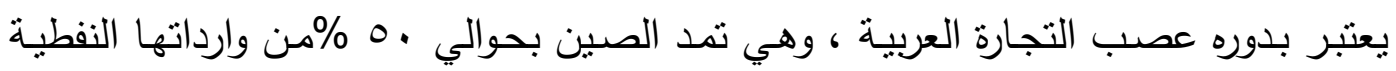
والمملكة العربية السعوديه على وجه التحديد تعد الممول النفطي الاول بين هذه الدول( . (Abdullah Y.1A وتسليط الضوء على تاثير القوة الناعمة للصين تجاه الدول العربية متخذين من دول

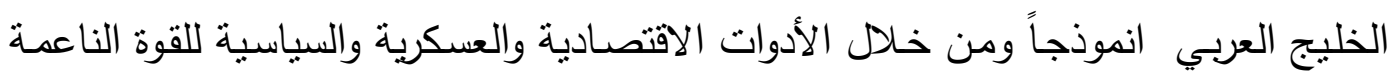

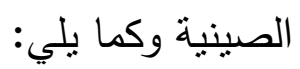
أولاً: الأدوات الاقتصادية يشير الباحثون الى أن الاهتمام الصيني بالخليج العربي يستتد الى عدد من الاعتبارات؛ الاديه

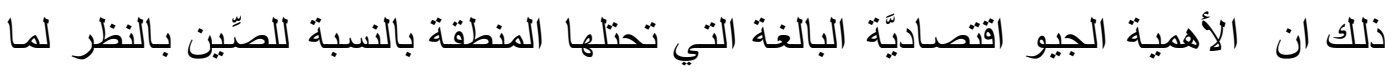

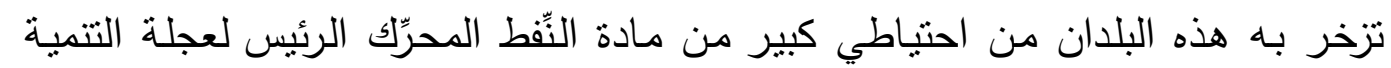

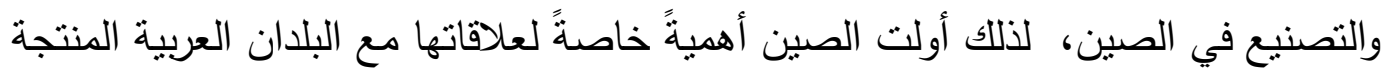

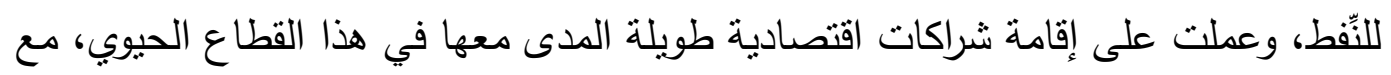


تقديم أفضل العروض لمنافسة الثّركات الأوروبية والأمريكيّة التي تحكمت لعقود طويلة

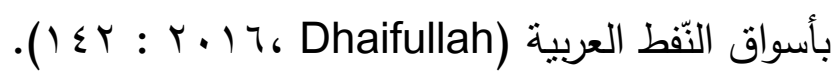

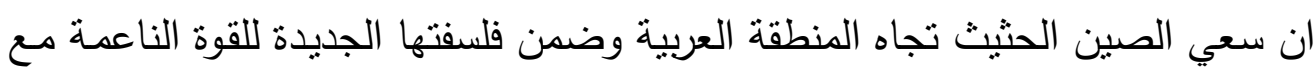

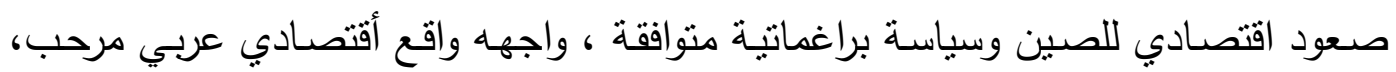

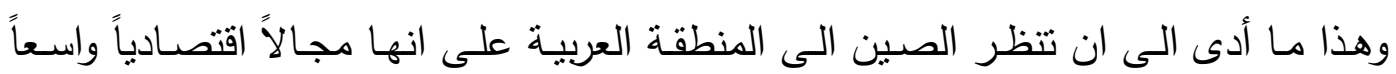
للاستثمار وللصادرات الصينية ، فضلا عن كونها مخزن مهم للطاقة في ادارة وادامة عجلة

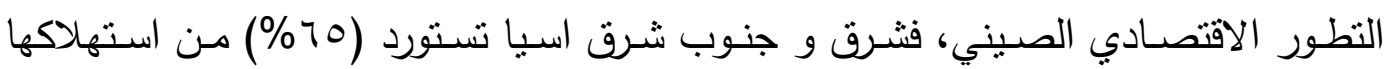

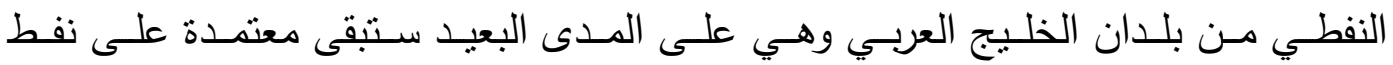

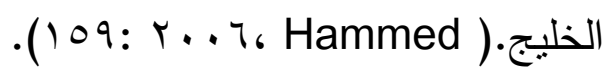

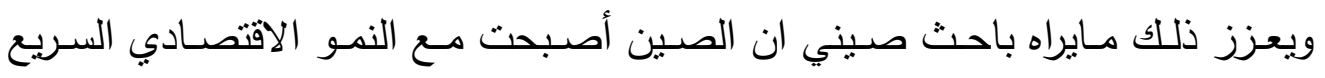

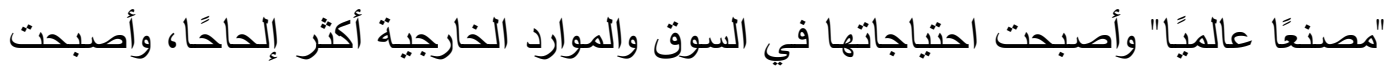

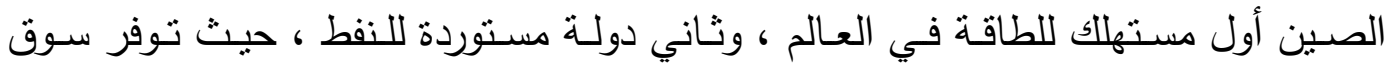

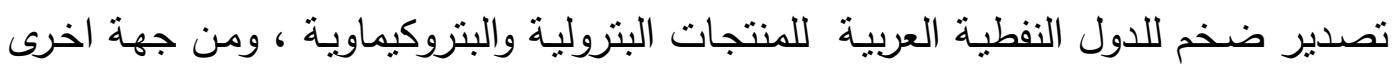

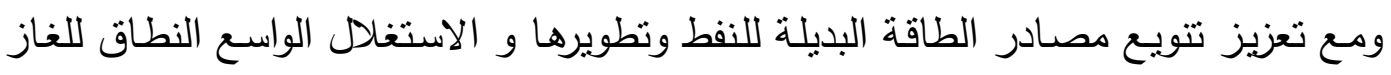
الصخري تعمل الدول الغربية وخاصة الولايات المتحدة على تقليل اعتمادها على نفط الدول العربية وبالتالي تحتاج تلك الدول إلى زيادة الجهود لنطوير أسواق جديدة ، مما ولد لديها

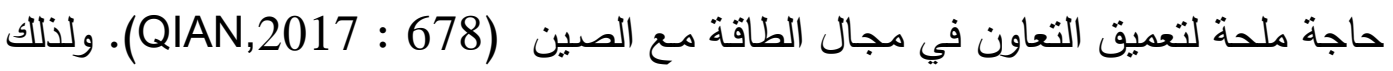

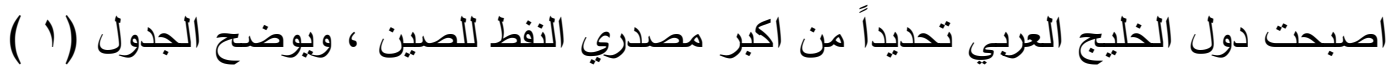
الاتي اكبر موردي النفط للصين على مستوى العالم : الجدول ( ) يوضح اكبر موردي النفط للصين على مسنتى العالم

\begin{tabular}{|c|c|}
\hline نسبة اجمالي الواردات & 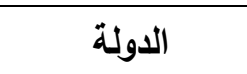 \\
\hline$\%$ \%.، & السعودية العربية \\
\hline$\% 14$ & أنغولا \\
\hline$\% 11$ & روسيا \\
\hline$\% 1$. & عمان \\
\hline$\% 9$ & العراق \\
\hline$\% 9$ & ايران \\
\hline$\%\{$ & فينزويلا \\
\hline$\% r$ & الامارات \\
\hline$\%$ & الكويت \\
\hline$\%$ & كولومبيا \\
\hline
\end{tabular}

QIAN Xuming \& Jonathan FULTON, China-Gulf Economic : المصدر Relationship under the "Belt and Road" Initiative , Asian Journal of Middle Eastern and Islamic Studies, Vol. 11, No. 3 , 2017, p13. 
ويمثل الثكل التالي اهم الدول الدصدرة للنفط الى الصين وعلى راسها السعودية وكما

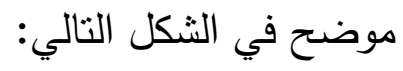

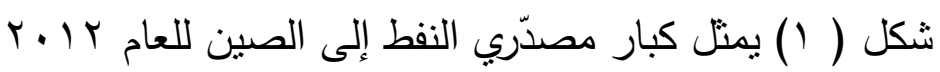

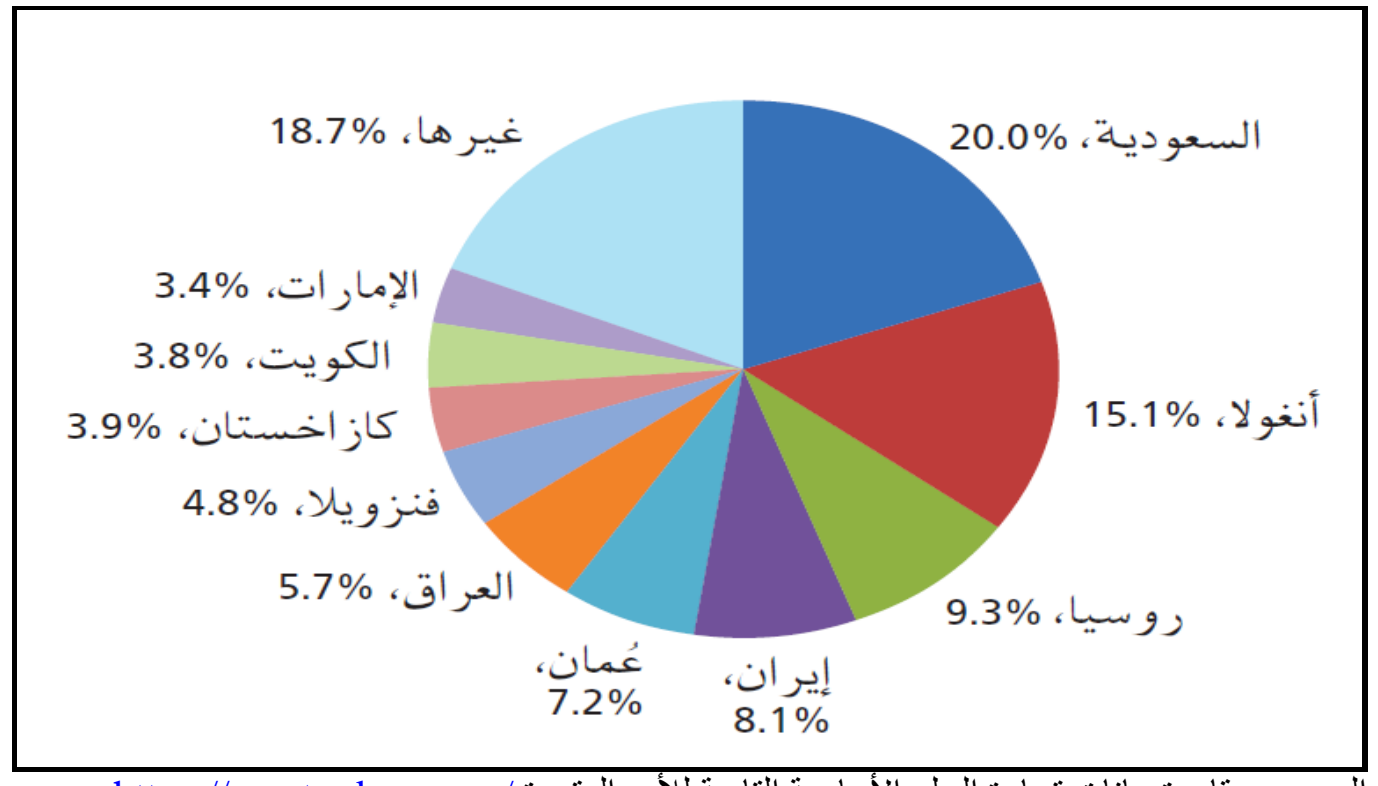

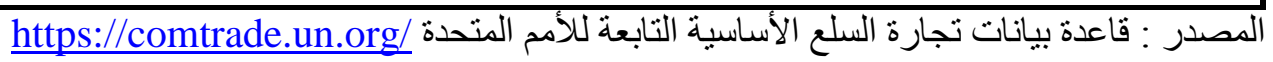

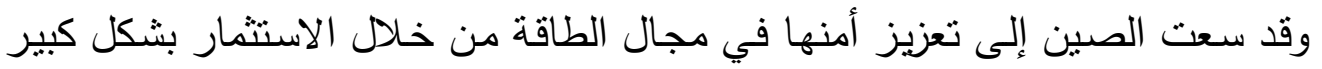

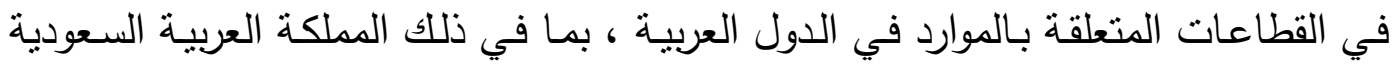

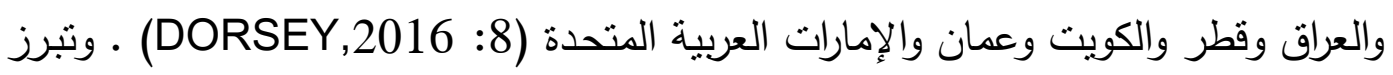

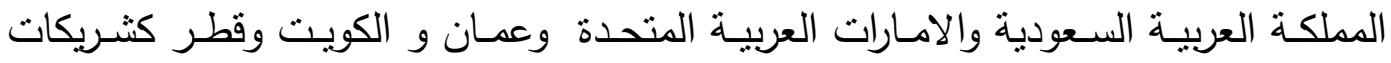

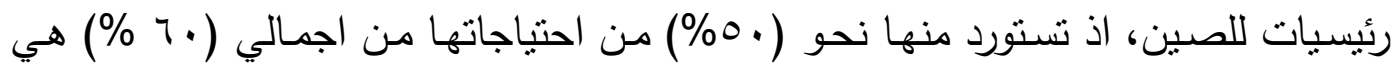

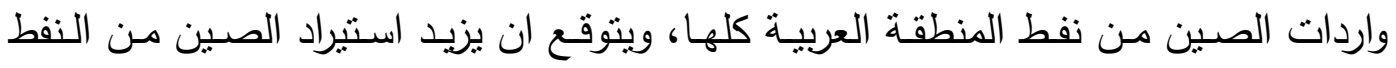

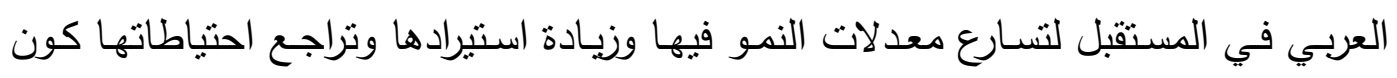

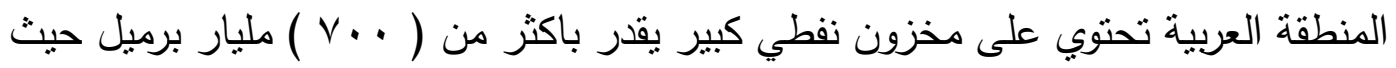

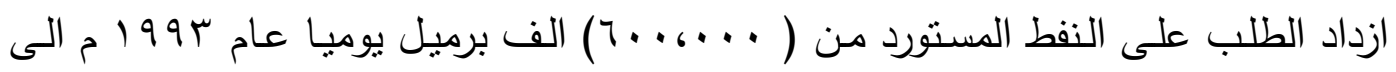

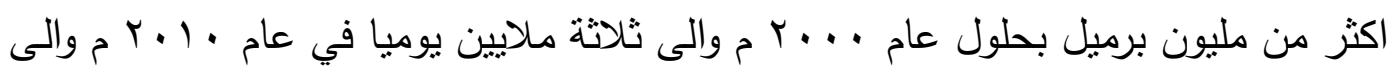

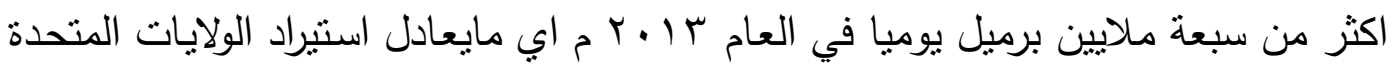

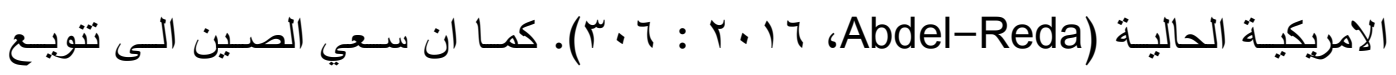
مصادر إمدادها بالنفط من الدول العربية على مر السنين ، جعها تطور علاقتها النفطية

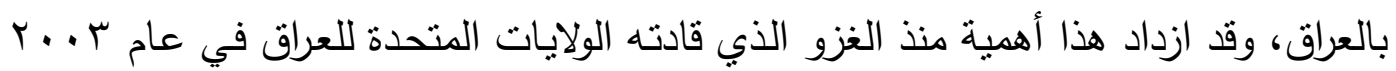

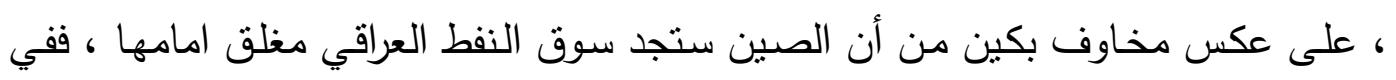

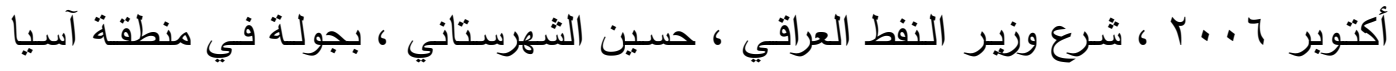

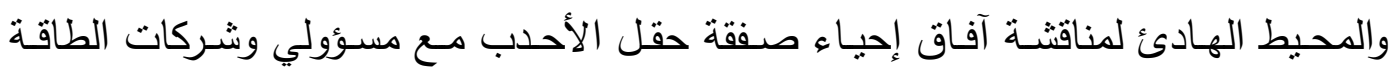


الصينية، كما زار الرئيس العراقي آنذاك جلال طالباني ، بكين عام V . . ب لمناقثنة أثنكال جديدة من التعاون ( 8: Daojiong \& Meidan,2015).

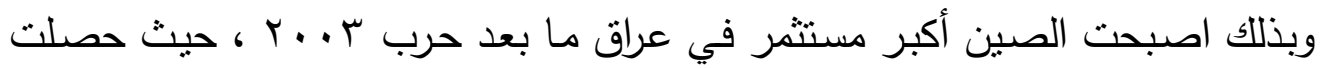

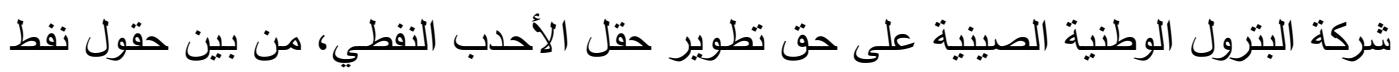

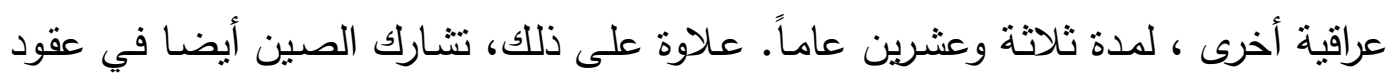
بناء مشتركة مع الثركات المحلية ( 14: Osman,2017). كمـا ان دول مجلس التعـاون الخليجي لعبـت دوراً مهمـاً في استراتيجية امـن الطاقـة

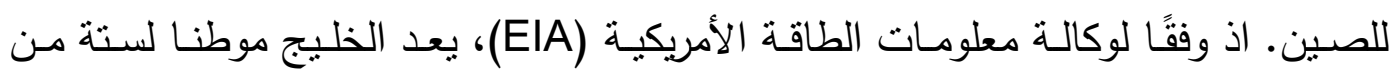

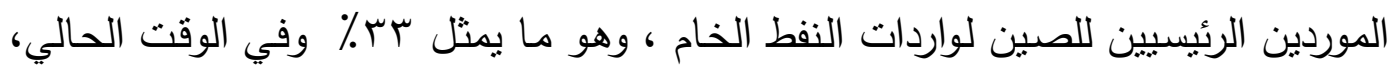

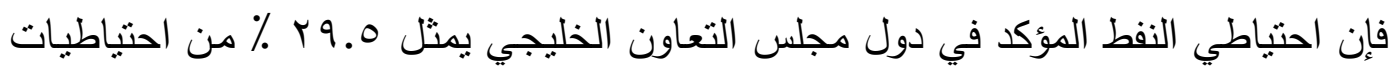

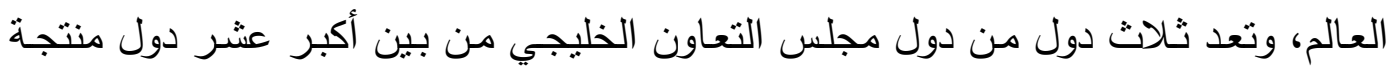

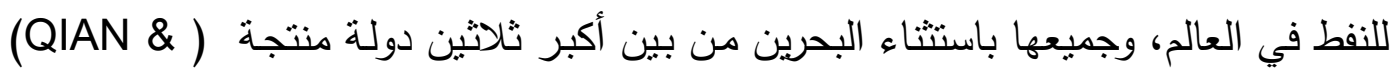
3: Fulton,2017.ويوضح الجدول (r ) التالي احتياطيات النفط في دول الخليج العربي:

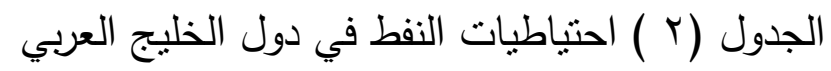

\begin{tabular}{|c|c|c|}
\hline التصنيف العالمي & احتياطيات النفط (مليارات للبرميل) & الدولة \\
\hline r & หั7.० & السعودية العربية \\
\hline 7 & 1.1 .0 & الكويت \\
\hline$v$ & $9 \vee . \wedge$ & الامارات \\
\hline $1 \leqslant$ & rO.r & قطر \\
\hline rr & $0 . r$ & عمان \\
\hline 79 & - & البحرين \\
\hline
\end{tabular}

Xuming QIAN \& Jonathan FULTON, China-Gulf Economic Relationship under the "Belt and Road" Initiative , Asian Journal of Middle Eastern and Islamic Studies, Vol. 11, No. 3 , 2017, p13.

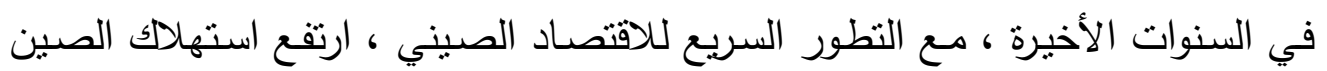

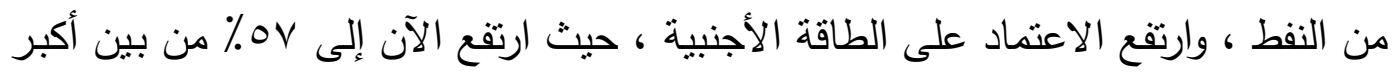

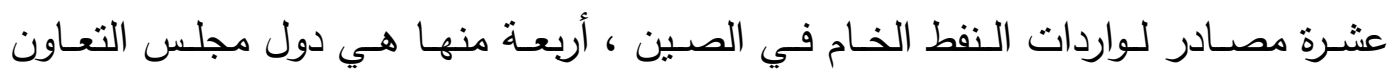

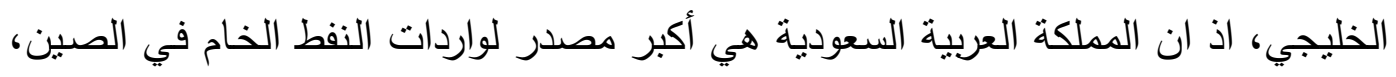

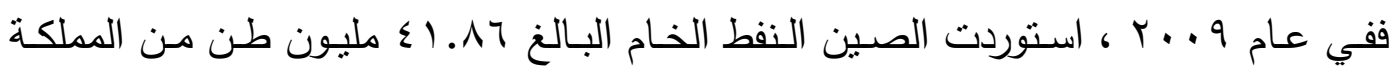

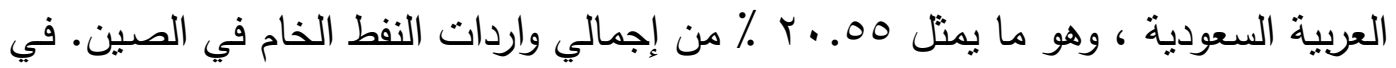




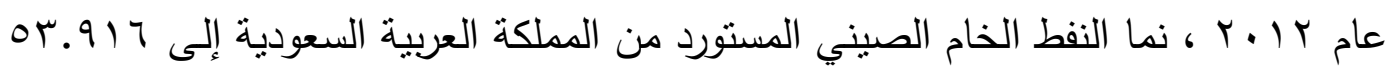

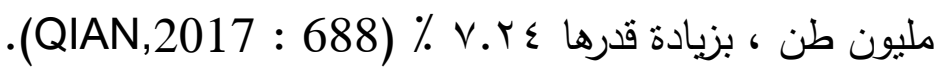

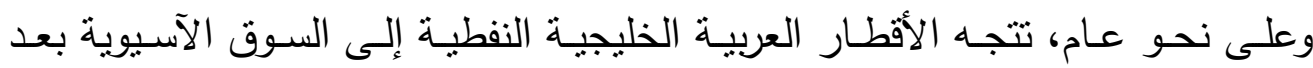

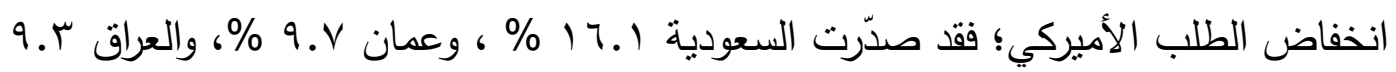

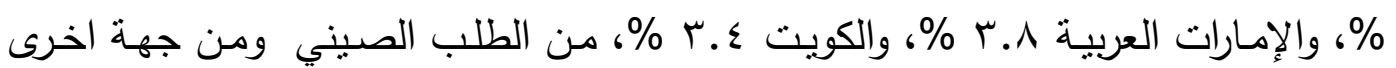

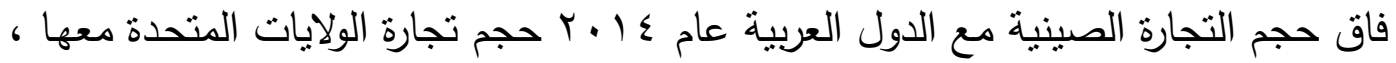
وتتصدر الدول الخليجيـة ( السعودية والإمـارات العربيـة والعراق) قائمـة الثـركاء التجـاريين

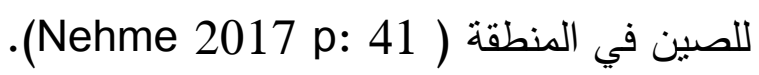
ولقد ازدادت أهمية العراق بالنسبة للصين مع تراجع واردات النفط الصينية من إيران

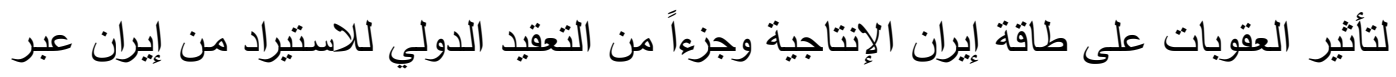

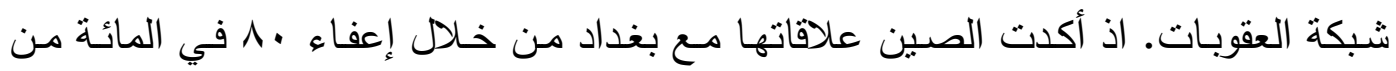
ديون العراق البالغة ه. 1 مليارات دولار وتوقيع صفقات تجارية بمليارات الدولارات في مجال منال

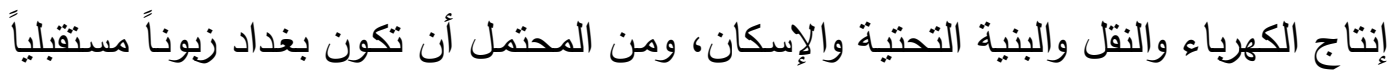

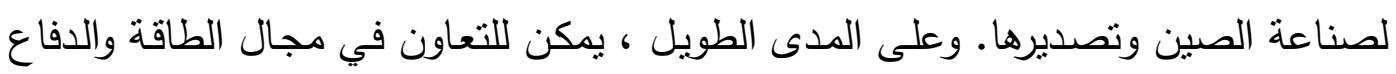
أن يساعد في تحديد استراتيجية جديدة بين البلدين ( 28: 2013, Salem).

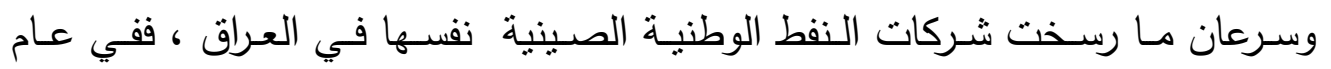

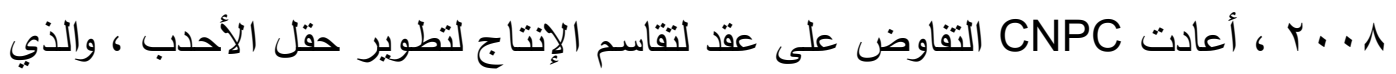

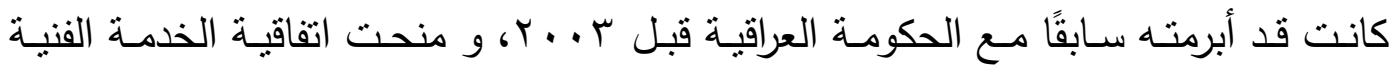

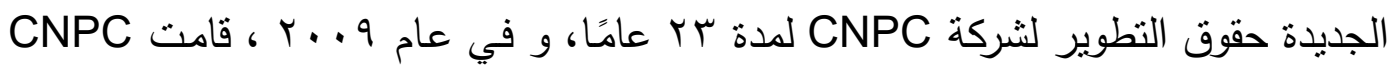
بالاشتراك مع شركة BP البريطانية في كونسورتيوم بالفوز بحق تطوير حقل الرميلة وزيادة

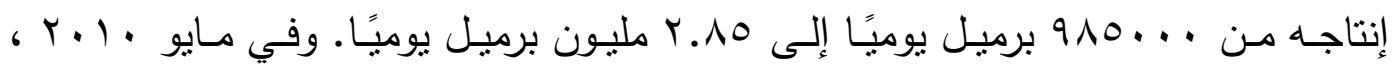

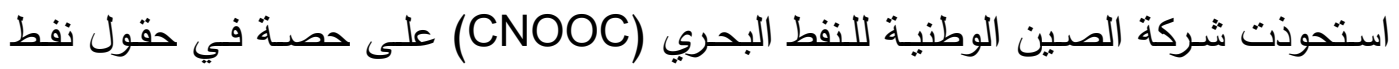

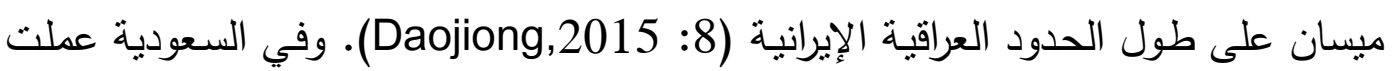

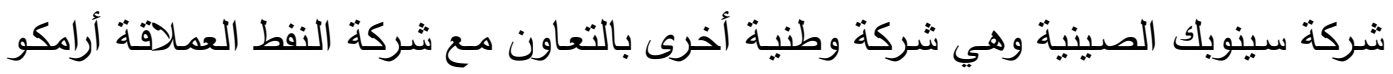

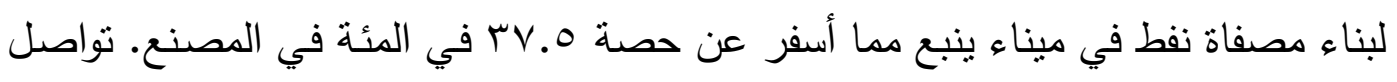
الصين توقيع صفقات نفطية ضخمة ، مما يزيد نفوذها في المنطقة ( Osman,2017).

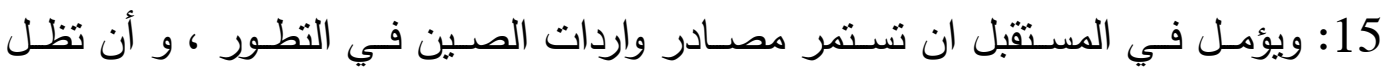

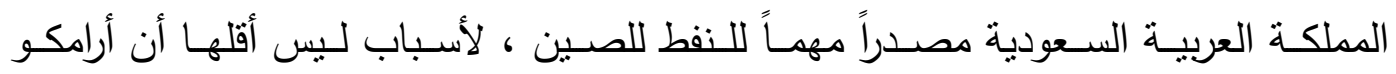

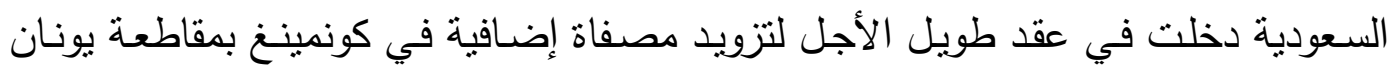
.(Daojiong \& Meidan,2015:7) 
وقد كان للصين مصالح اقتصادية أخرى لها دورها في تحديد طبيعة التوجه للقرار

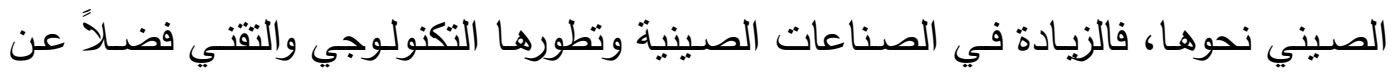
المنافسة الثديدة بين الصين وباقي القوى الاسيوية والغربية وخاصة اليابان والولايات المتحدة الهردية

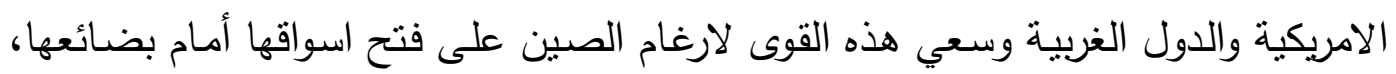

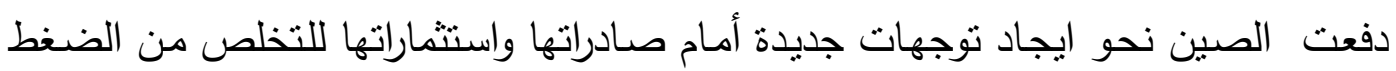

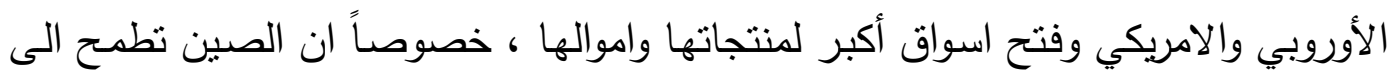

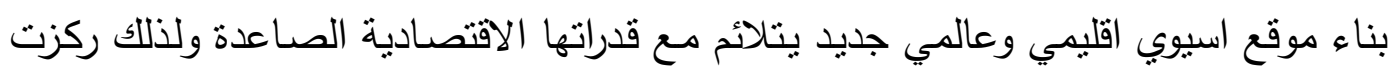
على المنطقة العربية والخليجية على وجه الخصوص في مجال الاستثمار كونها تمثل ركيزة أساسية لتحقيق طموحها العالمي ( Hammed 2006 p:161 ). وتؤكد الدول العربية بما فيها الخليجية على ان تكون الصين شريكا تجاريا لها ، وان ينت التبادل في الاستثمارات الصينية-العربية مع بعضها، واضافة للتجارة البينية بين الطرفين

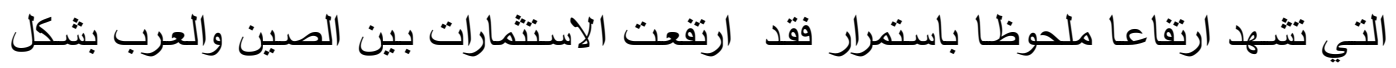

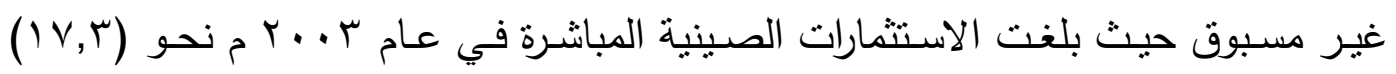

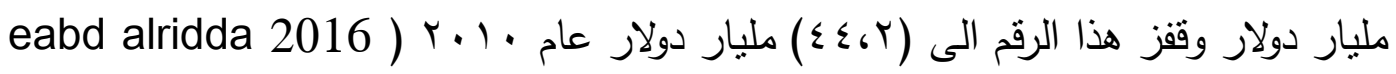

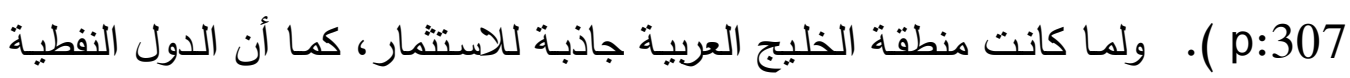

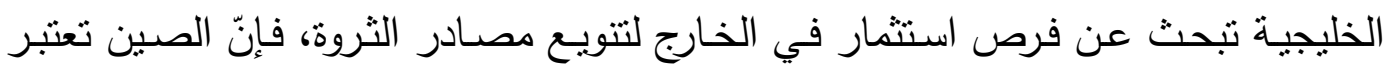

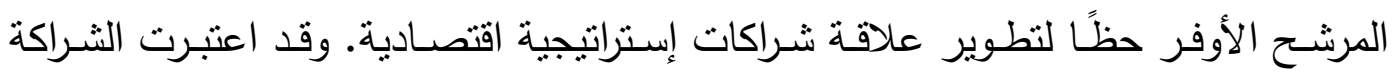
الإستراتيجية تلك مسهلة للهدف الصيني الجديد في إستراتيجية (التححور في الغرب) التي

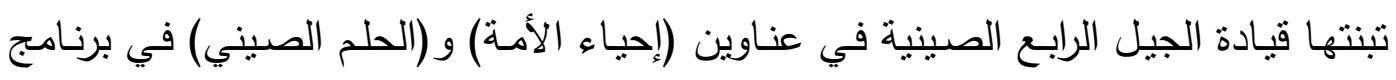

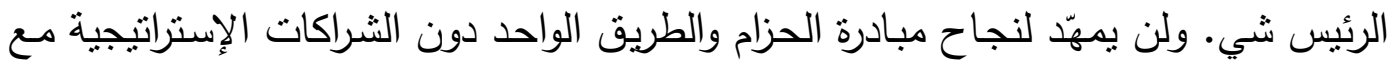

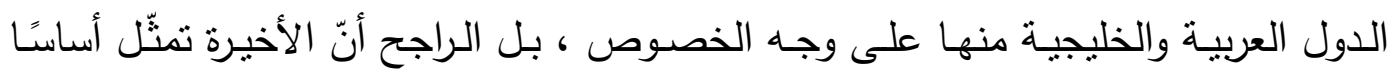

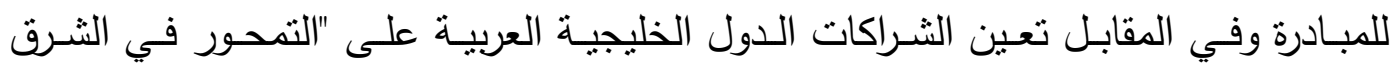
.(Nehma 2017p:41)

كما ان المنتجون الخليجيون الاخرون سعداء بالاستثمار في المصافي الصينية التي من

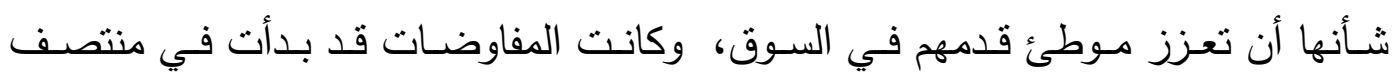

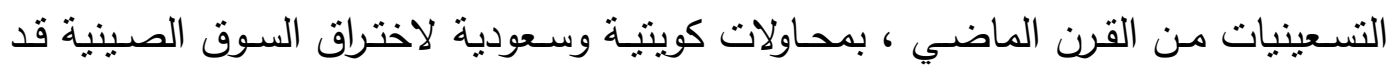

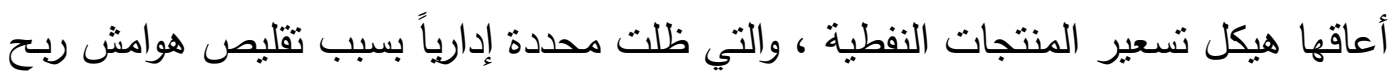

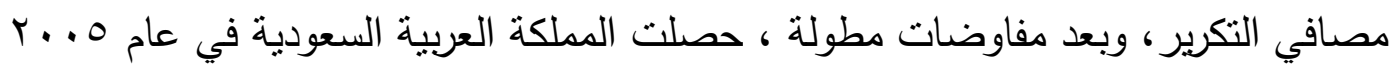

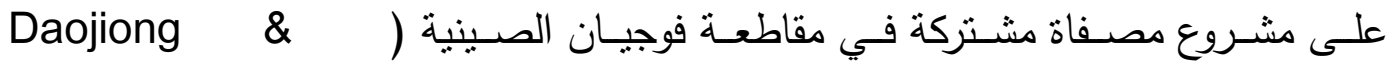


من جهة اخرى فان تعزيز التعاون التجاري والاسثماري بين الطرفين تزايد في وقت يتعاظم فيه التطرف و التعصب ضد العرب من بعض دول الغرب خاصنة (الولايات المتحدة

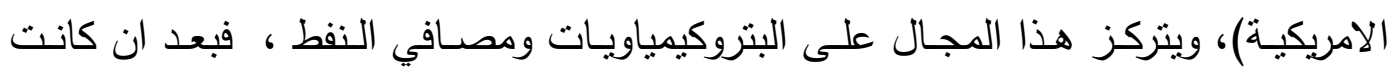

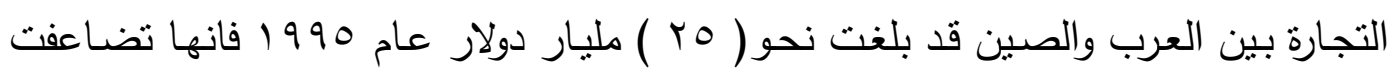

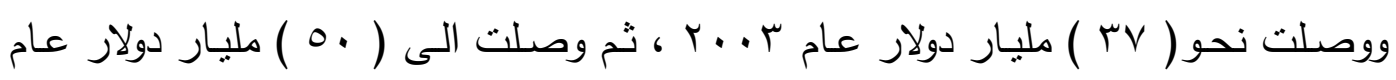

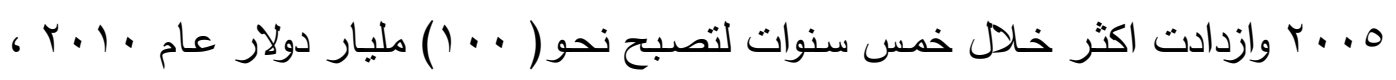

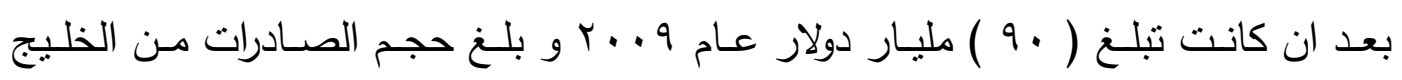

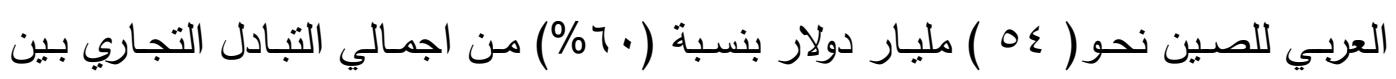

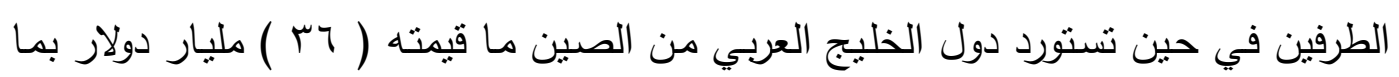

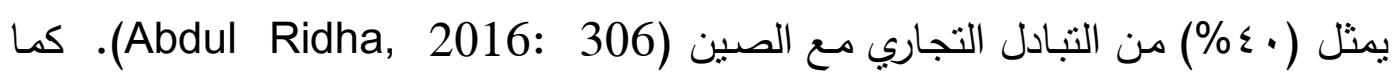

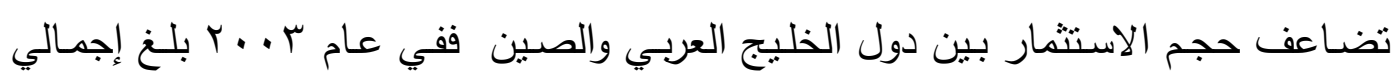

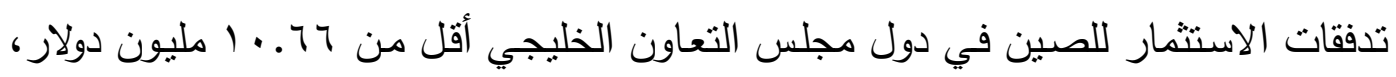

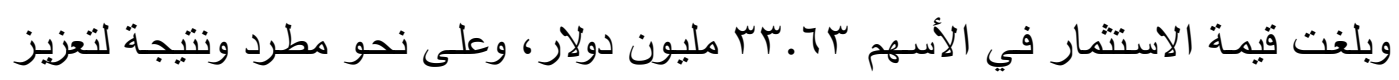

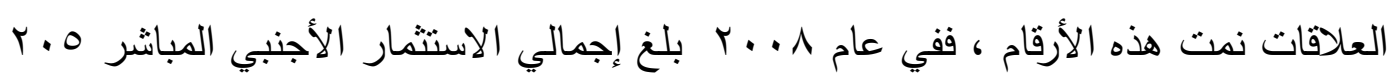

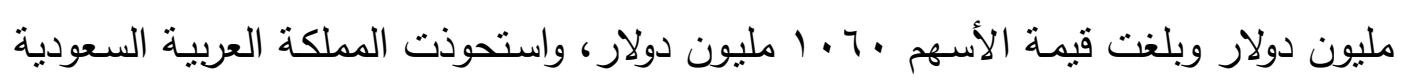

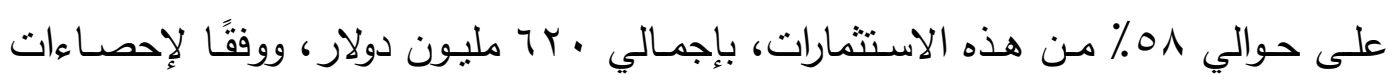

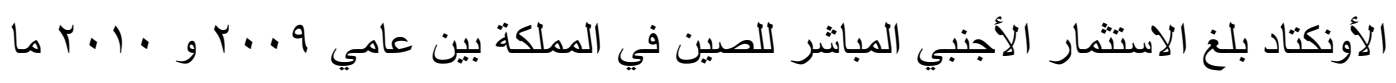

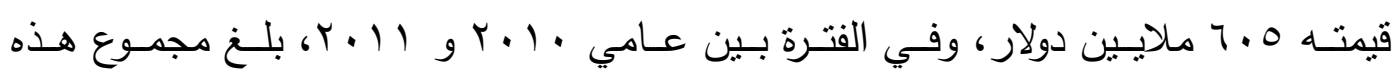
الاستثمارات (197 197 مليون دولار (30 : Al-Sudairi,2012).

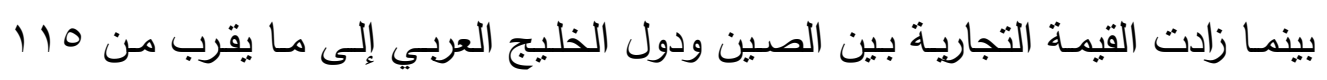

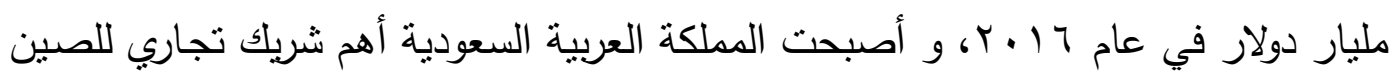

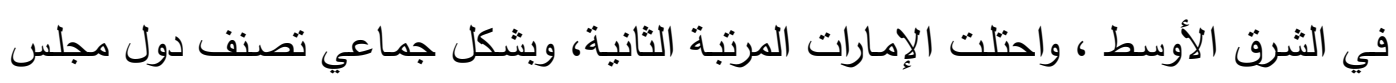

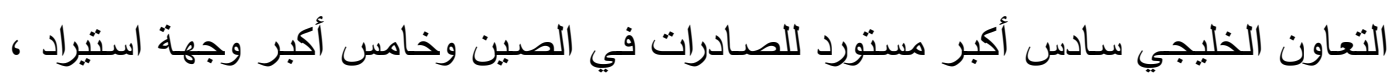

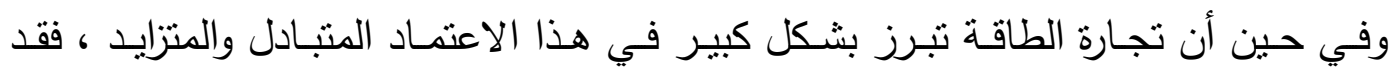

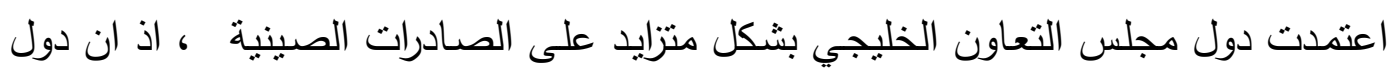

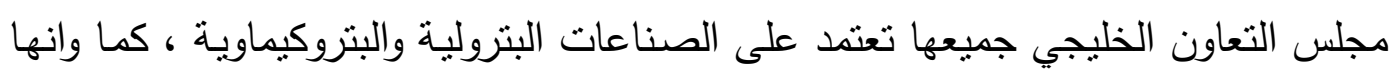

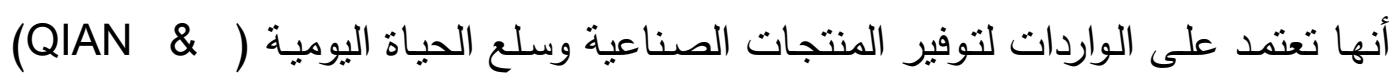

.Fulton, $2017: 3$

وخلال زيارة شي جين بينغ وزير الخارجية الصيني للمملكة العربية السعودية في عام

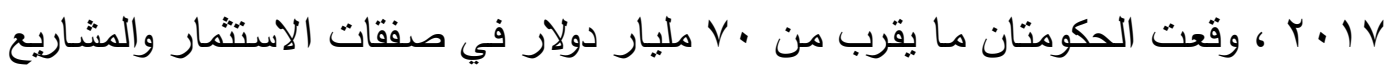


المشتركة بين الثـركات الصينية والسعودية في قطاعات الطاقة والبتروكيماويات والطاقة المتجددة ونقل التكنولوجيا (6: BENABDALLAH,2018)

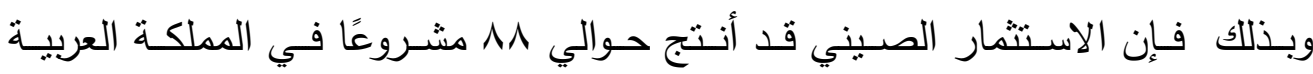
السعودية، و من بين هذه كان با كشروع ذات طبيعة صناعية حيث قدم الجانب الصيني ؟ ؛ في المائة من رأس المال ، في حين أن الصينيين في المشاريع السبعة والسبعين الأخرى

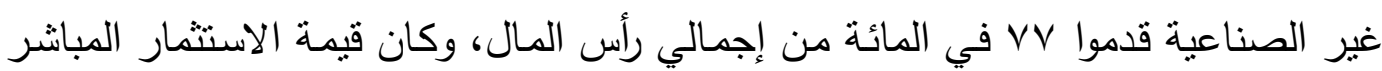

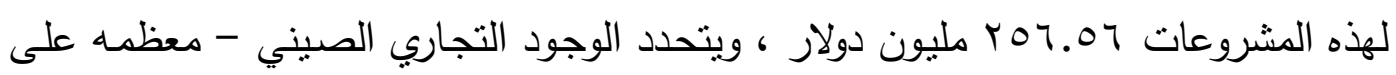

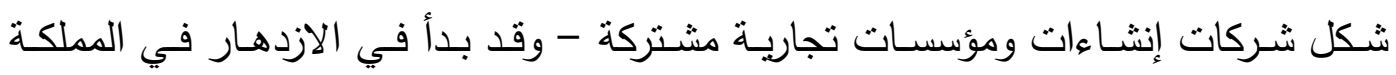

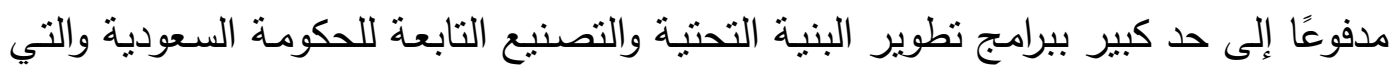

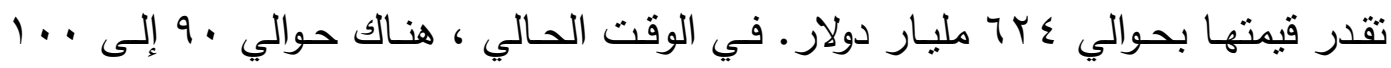

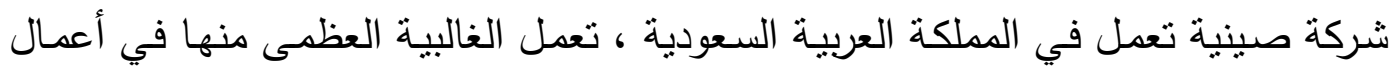

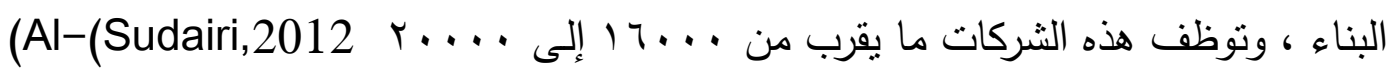

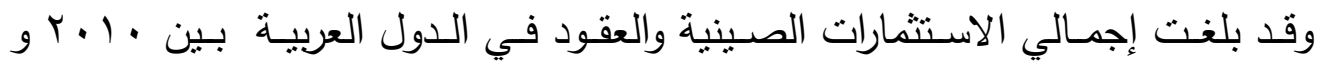

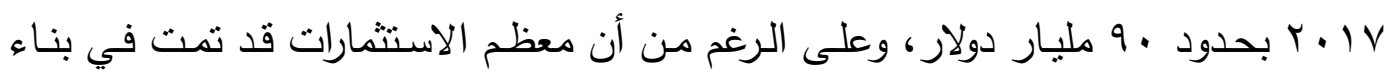

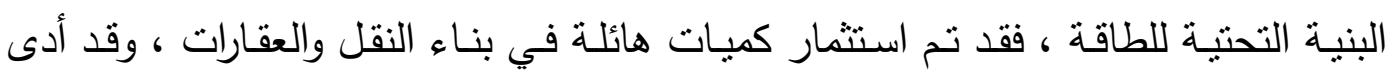

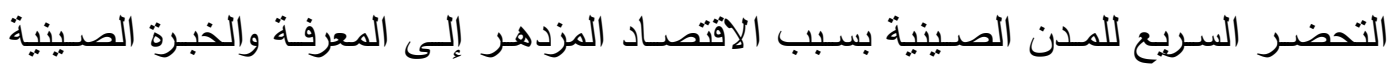

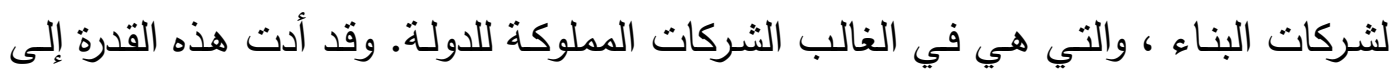
توفير فرص جديدة في المناطق التي يرتفع فيها الطلب على البنية التحتية في الدول العربية

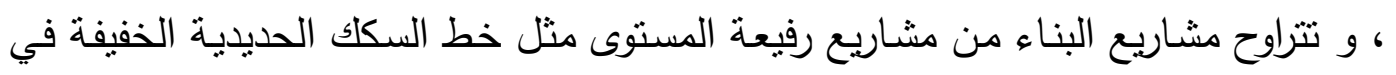

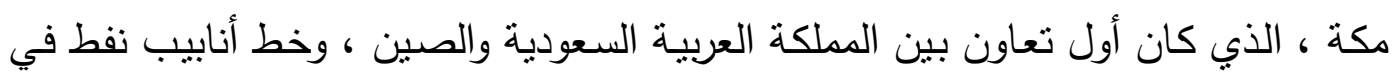

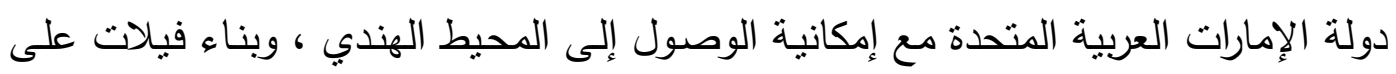
نخلة دبي الثهيرة ( 15: Osman,2017).

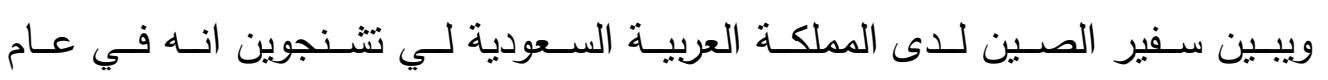

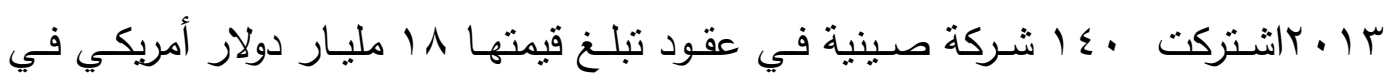

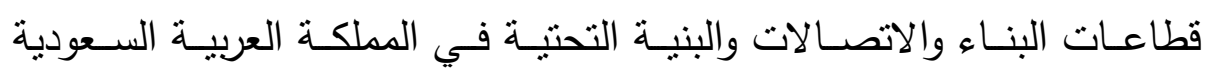

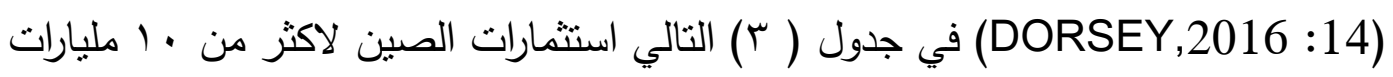

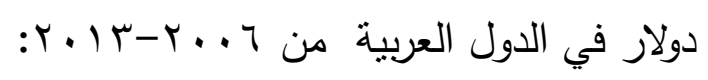


جدول (T) يوضح استثمارات الصين لأكثر من · ( مليارات دولار في الدول العربية

\begin{tabular}{|c|c|c|c|c|c|c|}
\hline سنة اول & المستثرين & الاستثمار & الثريك / المستهـف & القطاع & الفرعي القطاع & البلا \\
\hline$r \ldots r$ & Citc \& chinalco & $9 \leq$. & & الفلزات & الالمنيوم & مصر \\
\hline$r \ldots v$ & China ocean & 10. & & المواصلات & الثحن & مصر \\
\hline$r \cdots v$ & xhinalco & $1 . r \ldots$ & شركة بن لادن & فظزات & الالمنيوم & السعودية \\
\hline$r \ldots \wedge$ & sinochem & $\varepsilon v$. & شركات نفط الجنوب & الطاقة & النفط & اليمن \\
\hline$r \ldots 1$ & cnpc & $r . \cdot r$. & & الطاقة & النفظ & العراق \\
\hline$r \ldots q$ & Tainjin & rA. & & العقارات & الاملاك - اك & مصر \\
\hline r..qq & cnoc & $1 \ldots$ & شركة قطر للبترول & الطاقة & كاز & قطر \\
\hline$r \ldots q$ & cnpc & $r \leqslant$. & وشروكة نفط الحكومية تلفويقي & الطاقة & النفط & العراق \\
\hline$r .11$ & sinpoec & $r . \mu \ldots$ & SABC & الطاقة & النفط & السعودية \\
\hline$r \cdot T^{T}$ & Jushi group & Tr. & & & الزاليانية & مصر \\
\hline
\end{tabular}

Source : JAMES M. DORSEY, CHINA AND THE MIDDLE EAST: VENTURING INTO THE MAELSTROM, S. RAJARATNAM SCHOOL OF INTERNATIONAL STUDIES ,SINGAPORE, 2016,P8.

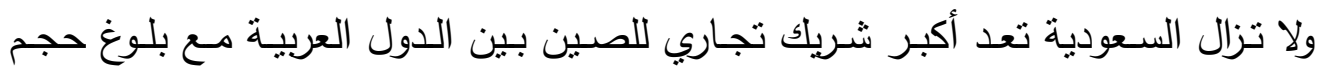

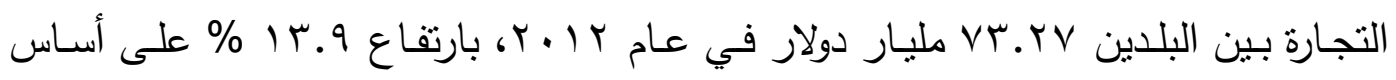

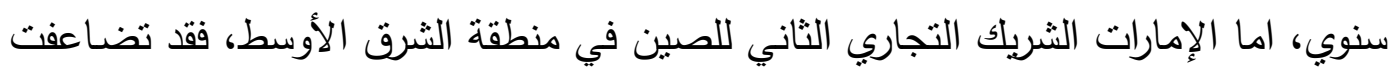

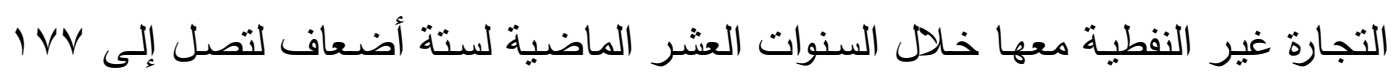

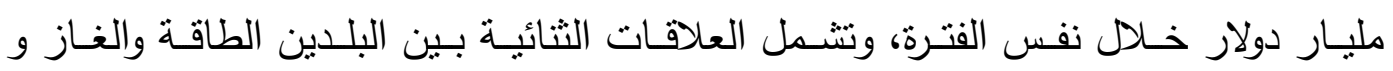

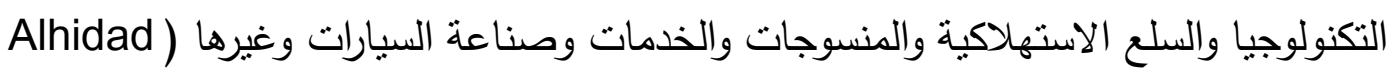

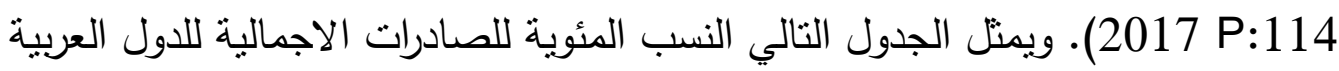

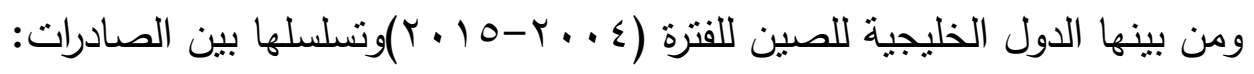
جدول (ع ) صادرات الدول العربية الاجمالية للصين

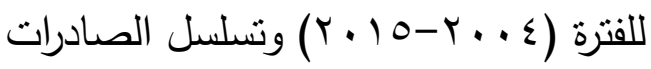

\begin{tabular}{|c|c|c|}
\hline ترتيب الصادرات لصين & نسبة الصادرات الى الصين & الدول العربية \\
\hline 1 & $\% 0 \leqslant$ & السودان \\
\hline 1 & $\%$ \% & عمان \\
\hline 1 & $\%$ rq & اليمن \\
\hline$T$ & $\%{ }^{\mu r}$ & موريتانيا \\
\hline 1 & $\% r^{T}$ & العراق \\
\hline 1 & $\% 10$ & السعودية \\
\hline $\bar{Y}$ & $\% 1 \pi$ & الكويت \\
\hline$r$ & $\% \mathrm{~V}$ & الامارت \\
\hline$r$ & $\%$ \% .r & الصومال \\
\hline
\end{tabular}




\begin{tabular}{|c|c|c|}
\hline$\varepsilon$ & 099.7 & ليبا \\
\hline$\varepsilon$ & $\% 7.0$ & قطر \\
\hline 7 & $\% \varepsilon . \wedge$ & الاردن \\
\hline 9 & $\%$ & مصر \\
\hline 11 & $\% 1 . \wedge$ & المغرب \\
\hline $1 \varepsilon$ & $\% 1.1$ & جيبوتي \\
\hline $1 \varepsilon$ & $\% 1.1$ & تونس \\
\hline IV & $\% 1.1$ & المغرب \\
\hline ro & $\% \leqslant . Y$ & جيبوتي \\
\hline M & $\% \cdot \because \leqslant 0$ & تونس \\
\hline m & $\% \cdot .79$ & الجز ائر \\
\hline$\varepsilon r$ & $\% \cdot .04$ & البحرين \\
\hline
\end{tabular}

https://atlas.media.mit.edu/en/visualize/tree_map/hs92/export/dza/chn/show/ $\underline{2015 /}$ يتبين مما سبق فعالية الادوات الاقتصادية الصينية تجاه الدول العربية عموماً والدول الخليجية خصوصاً ومدى تاثيرها كاحدى مصادر القوة الناعمة الصينية. ثانيا :الأدوات السياسية

في الجانب السياسي كان لنشوء القوة الناعمة الصينية انعكاسات منباينة بين الصين والدول العربية بحسب اراء الباحثين، فالصين تحاول إعادة التوازن إلى سياساتها الداخلية

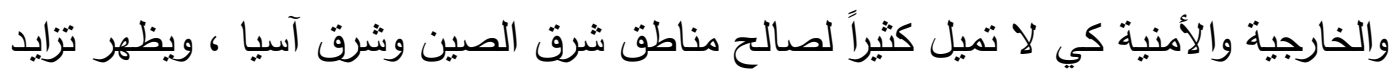

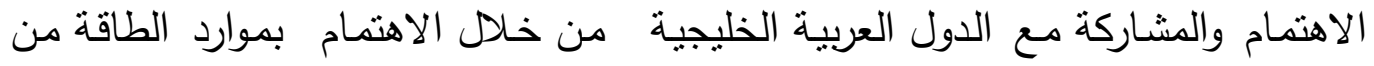

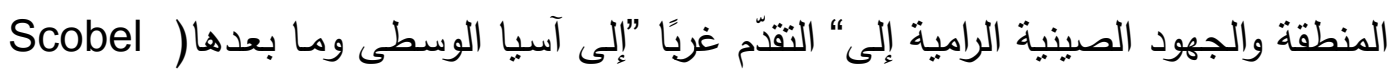
أ and Nader اخرى فهي من بين دول الحزام الثالث في مجال الصين في سياسة القوة الناعمة وإستراتيجية

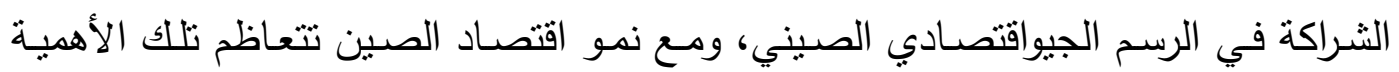

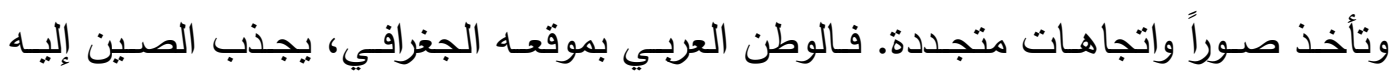

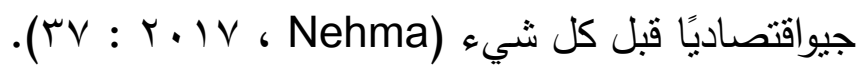
وقد وصفت السياسة التي انتهجتها الصين بالحكيمة ، فكانت سياسة قادرة على تقليص :لقالي

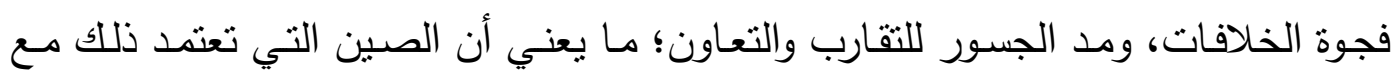

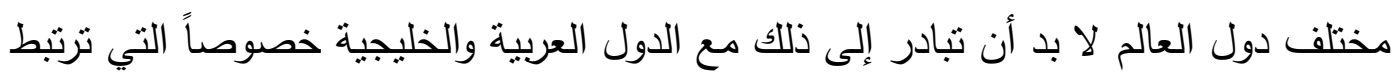

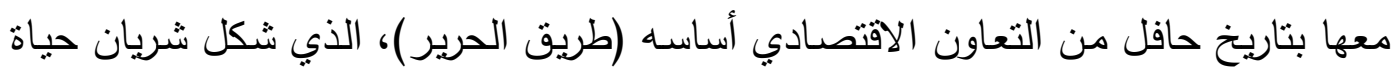
للمنطقة الممتدة من شاطئ البحر الأبيض المنوسط حتى بحر الصين، وعمل على تقريب

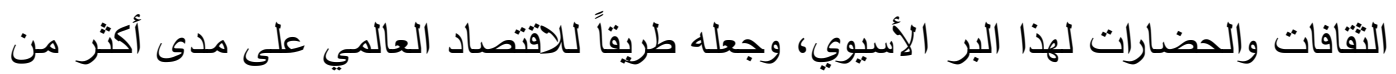

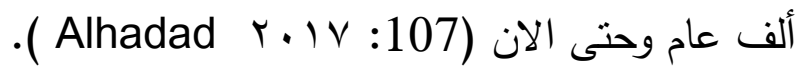


وفي المقابل تحاول الدول العربية الحصول على حليف قوي ليشكل قطبا موازيا للولايات المتحدة الامريكية في المرحلة القادمة ، لكون الصين هي احدى القوى الكبرى المعارضة

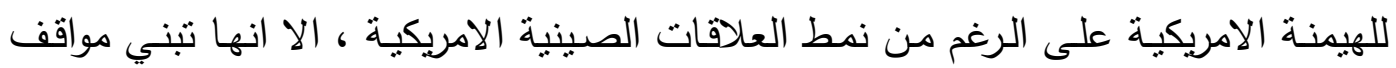

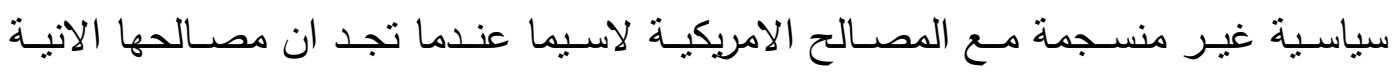
والمستقبلية تستلدي ذلك، فضـلاً عن رفضها للتندخلات الامريكية في الثؤون الداخليـة ،

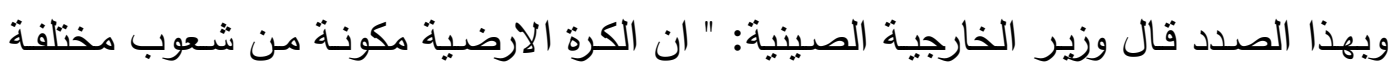

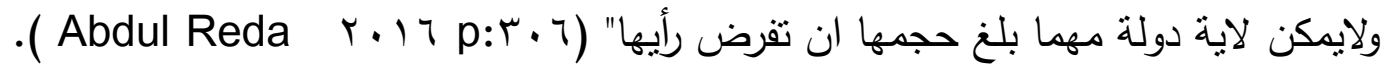

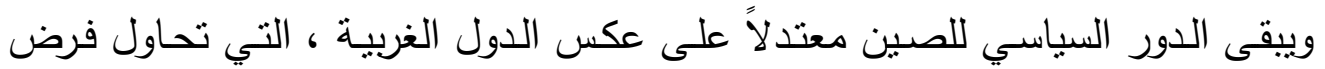

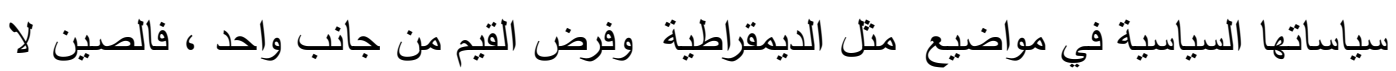

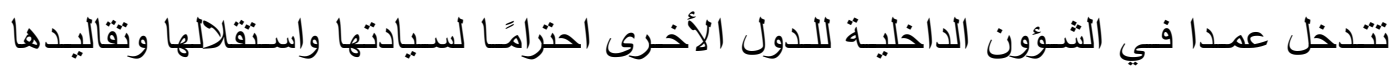
وأسـاليب حياتها، وتنهم هذه السياسـة غير التشخليـة في موقف الصـين البراغمـاتي تجـاه

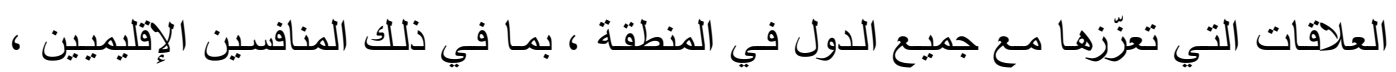
لأنها تعتقد أن العلاقات الجيدة تسهم في تحسين الفرص الاقتصادية ( Osman,2017).

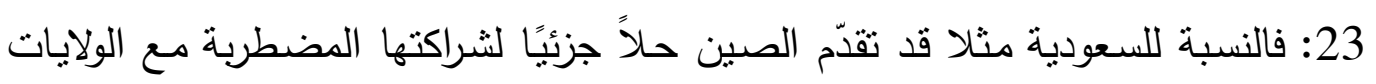

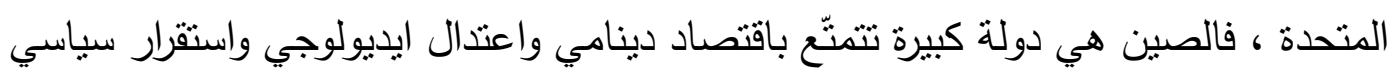

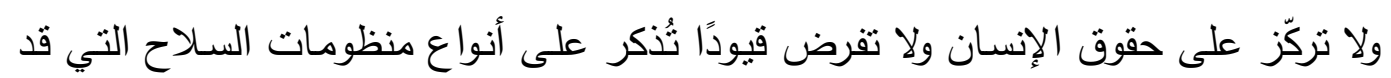

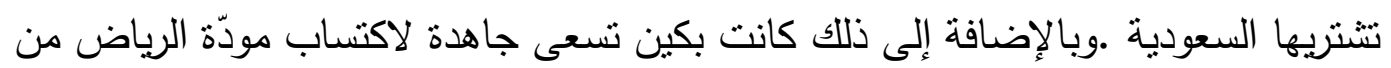

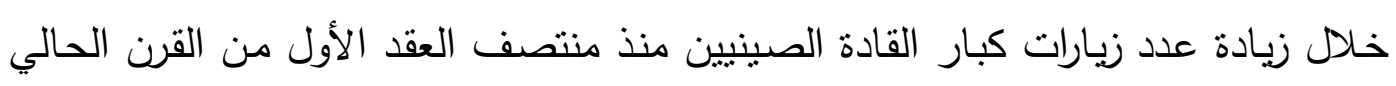
.(Andrew Scobel 2016 p:28) كما حافظت الصين على علاقات دبلوماسية طبيعيـة مـع جميع الدول الرئيسية في

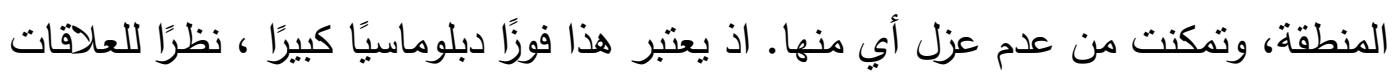

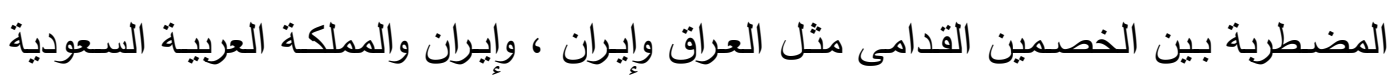
وفلسطين وإسرائيل (3: Benabdallah,2018). وعلى الرغم من التأييد الصيني لتسوية تاريخيـة للصـراع العربي - الإسـرائيلي، فقد

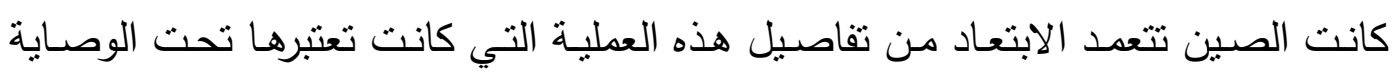

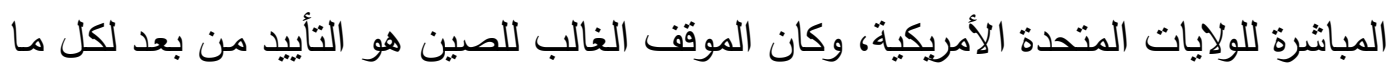

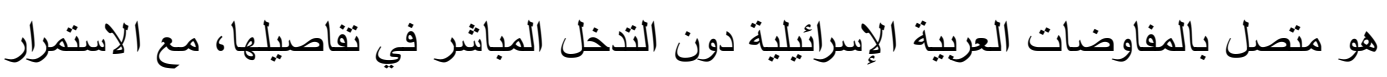

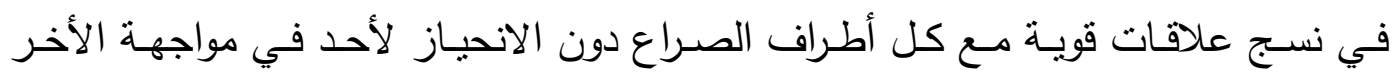
.(Alhadad 2017 p; 116 ) 
وإذ يلعب العامل الجيواستراتيجي دوراً مهماً ساهم في تطور العلاقات بين الطرفين،

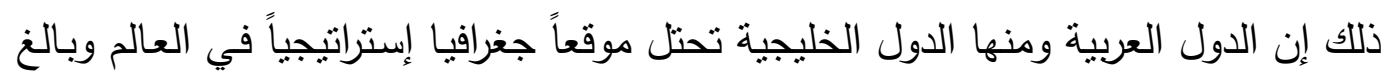

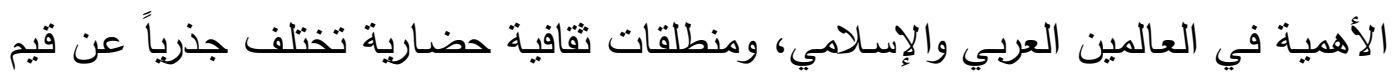

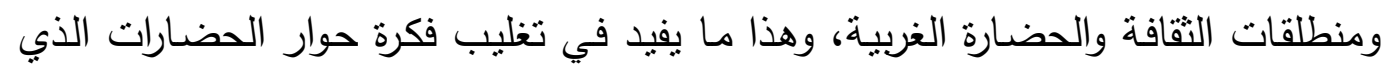

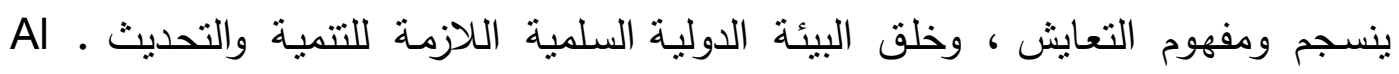

(Shaqaba) 2018p:381

وبالاضافة لما تقدم، وانطلاقًا من روح السياسة الخارجية كونها وظيفة للسياسة الداخلية،

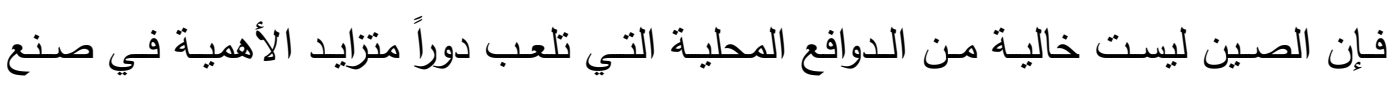

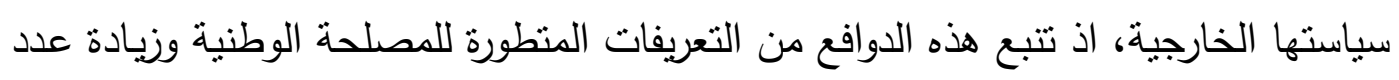

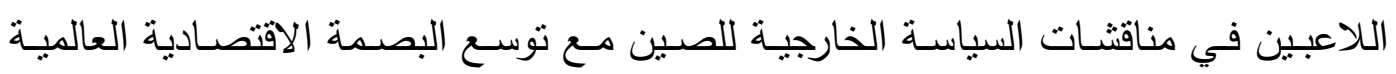

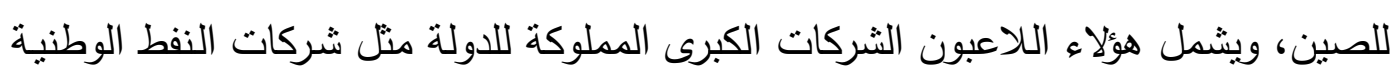

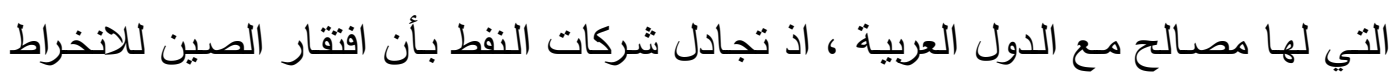

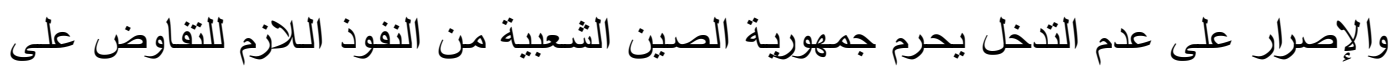

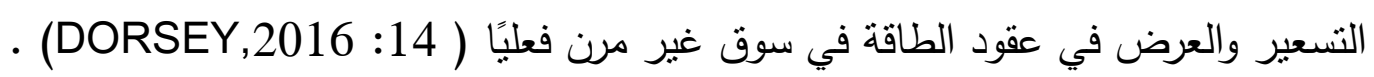

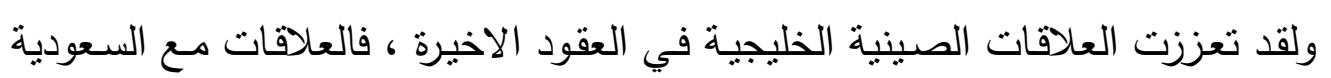

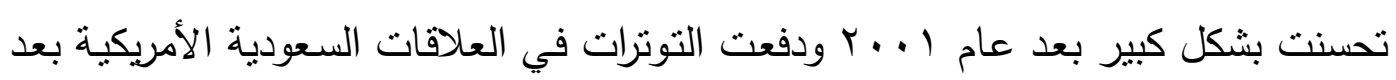

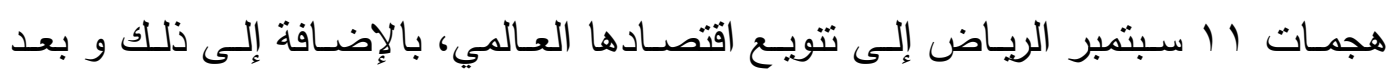

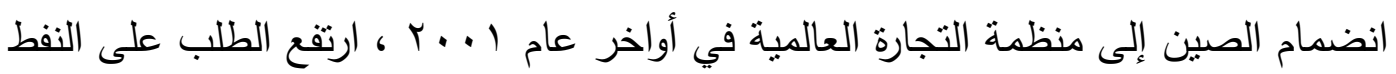

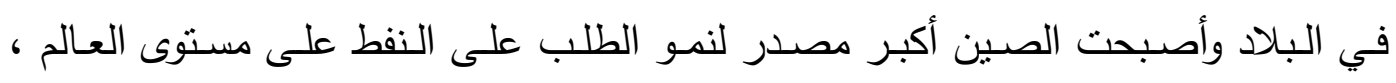

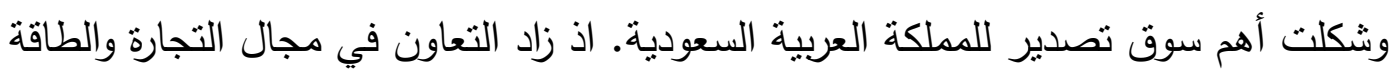

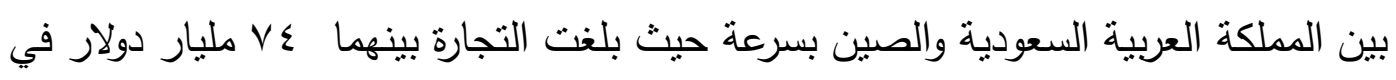

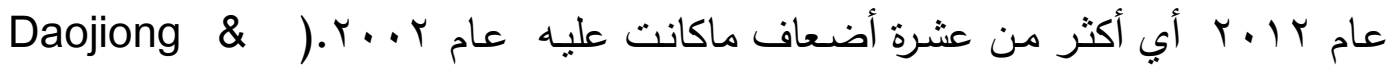

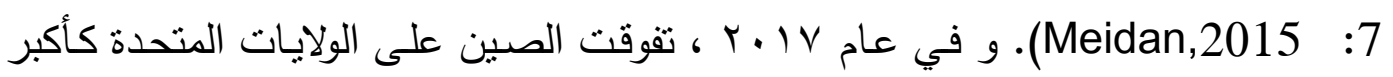

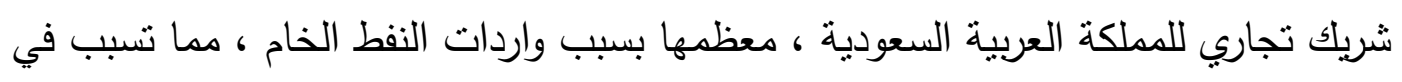
تقارب العلاقات بين الصين والسعودية (6: Benabdallah,2018).

الاستنتاجات 1. تنين تعاظم القوة الناعمة الصينية المستمر منذ بداية القرن الحادي والعشرين، اذاستطاعت

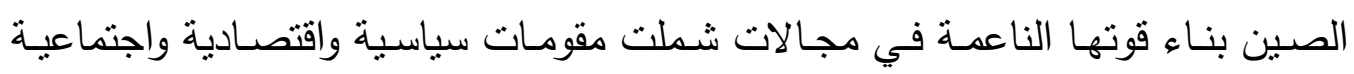
وتكنلوجية). 


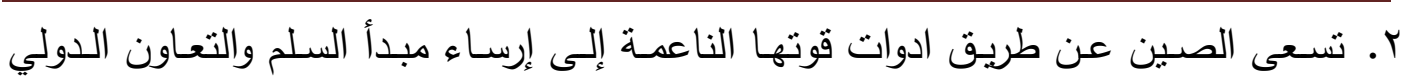

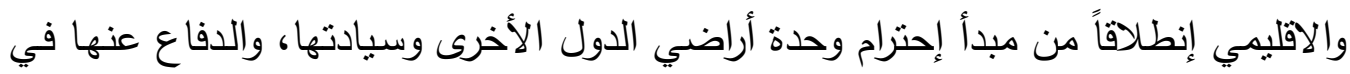
حالة التعرض إلى تهديدات خارجية .

r. ان الاهتمـام الصيني بمنطقـة الخليج العربي بادلته دول الخليج العربي بـفس الرغبـة

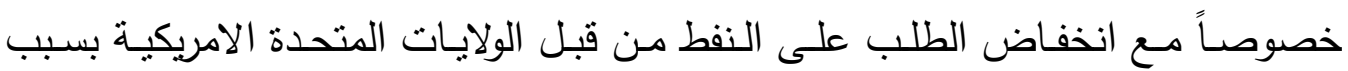
اكتثافات الوقود الاحفوري فيها.

ء. ان الصين سعت الى زيادة استتماراتها في منطقة الخليج العربي في الصناعات النفطية والغازية ومشاريع الانشاءات كي ترفع من مجالات التعاون مع دولها، ومن جهة اخرى لئي

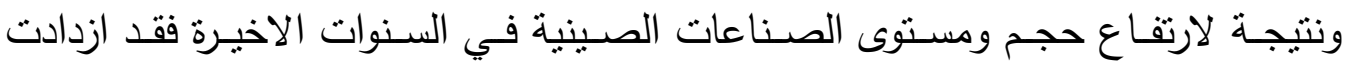
الصادرات الصينية لدول الخليج العربي واصبحت تحتل مراتب متقدمة في جدول وارداتها.

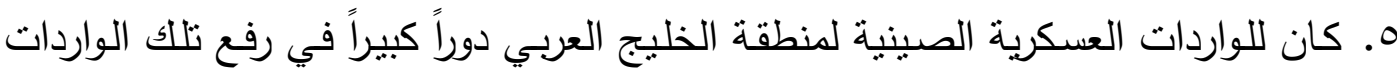
حيث مثلت الاسلحة الصينية اهم ادواتها العسكرية في المنطقة امام اشتراطات الولايات المتحدة الامريكية امام الدول التي تستورد اسلحتها .

T. ان الصين تسعى الى ايجاد دور مهم لها في المستقبل في حماية خطوط الملاحة الدولية في منطقة الخليج العربي لحماية مصالحها الاقتصادية المتتامية.

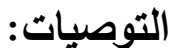

ا. ضرورة أخذ التجربة الصينية من قبل الدول العربية بنظر الاعتبار عند بناء تجربة للبناء الاقتصادي تمزج بين اقتصاديات السوق الحر وتوجيه الدولة له.

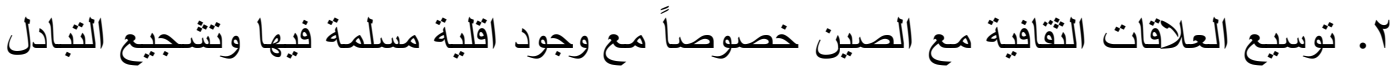

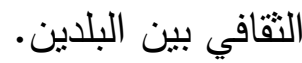

r. دراسة المنهج السياسي الصيني كنموذج متقدم من نماذج التعامل بين الدول واستخلاص

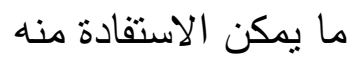

\section{References:}

1. Adnan Khalaf Hamid Al-Badrani, The Impact of Continuity and Change on Chinese Foreign Policy Towards the Middle East Peace Process, Al-Mustansiriya Journal for Arab and International Studies, Issue 49, 2015.

2. Ahed Muslim Al-Shaqaba, The Political Dimension of ArabChinese Relations and Their Future Prospects, Dirasat Journal, Human and Social Sciences, Vol. 41, Appendix 1, 2014.

3. Ahmed Qassem Hussein, Smart Power Approaches as a Mechanism of International Change: The United States of 
America as a Model, Arab Center for Research and Policy Studies, 2016.

4. Aisha Manafih, Determinants of China's Foreign Policy in the Middle East after the Arab Movement, a research published in the Research Journal - Publications of the Khaled Hassan Foundation - Studies and Research Center - Rabat, Volume One, 2014.

5. Ali Hussein Bakir, China's future in the world order (a study in the peaceful rise and soft power), $\mathrm{PhD}$ in Political Science, Department of Political Science, Faculty of Law and Political Science - Beirut International University, 2016.

6. Andrew Scobel and Ali Raza Nader, China in the Middle East, The Rand Santa Monica Foundation, California, 2016.

7. Belkacem Ben Deifallah, Report on the Seminar on China-Arab Relations: The Case of Algeria - Laboratory of Research and Studies in International Relations, University of Algiers, April 14, 2016, p. 141.

8. Beston Husen Arif, The Role of Soft Power in China's Foreign Policy in the 21st Century, International Journal of Social Sciences \& Educational Studies, 2017 ,Vol.3, No.3.

9. Carola Mc Giffert, Chinese Soft Power and Its Implications for the United States, Competition and Cooperation in the Developing World, A Report of the CSIS Smart Power Initiative, CENTER FOR STRATEGIC \& INTERNATIONAL STUDIES, 2009.

10.Charlene Tan\& Salleh Hairon, Education Reform in China: Toward Classroom Communities, Article · October 2016.

11.Chaudhry Saeed Ullah, CHINA'S SOFT POWER: CHANGING, THE WORLD PERCEPTION, MASTER OF SCIENCE IN , DEFENSE ANALYSIS (MIDDLE EAST, SOUTH ASIA, SUBSAHARAN , AFRICA), NAVAL POSTGRADUATE SCHOOL, 2015.

12.Daixing, et al, Research on soft power and its discipline ,orientation , International business and management, V 4 - n 1 2012.

13.Giulio m Gallarotti, Soft power : what it is , why it is important , and the conditions for ,its effective use, Wesleyan university ,Department of government ,2011. 
14.Hala Khaled Hamid, Development of Arab-Chinese Relations / Journal of Political Science, Issue 33, 2006, p. 160.

15.https://www.researchgate.net/publication/311992506_Education_ Reform_in_China_Toward_Classroom_Commun.

16.https://www.washingtoninstitute.org/ar/fikraforum/view/saudichinese-rapprochement-and-its-effect-on-saudi-american-relations

17.Ibrahim Nafi, China - The Miracle of the End of the Twentieth Century / - First Edition - Al-Ahram Center for Translation and Publishing - Cairo, 1999.

18.JAMES M. DORSEY, CHINA AND THE MIDDLE EAST: VENTURING INTO THE MAELSTROM, S. RAJARATNAM SCHOOL OF INTERNATIONAL STUDIES ,SINGAPORE, 2016.

19.JAMES M. DORSEY, CHINA AND THE MIDDLE EAST: VENTURING INTO THE MAELSTROM , S. RAJARATNAM SCHOOL OF INTERNATIONAL STUDIES ,SINGAPORE, 2016. ${ }^{1}$ Paul salem , Iraq's, tangled foreign interests and relations, Carnegie endowment for international peace all right reseved Carnegie middle east center, Lebanon, 2013.

20.Joshua Kurlantzick, China's Charm: Implications of Chinese Soft Power, Carngie endowment for international peace ,Policy brief , 2006 .

21.Kazem Hashem Nehme, Chinese and Arab Soft Power, Journal of Arab Studies, Issue 26 - May 2017.

22.Li Hongjie, China Road - The Secret of a Miracle, Egyptian Publications Office, 2014.

23.Ling $\mathrm{Li} \&$ Hongqiao $\mathrm{Fu}$, China's health care system reform: Progress and prospects, article in International Journal of Health Planning and Management 32(11) · June 2017.

24.Michael Chan, Microblogging, Online Expression rand Political Efficacy Among Young Chinese Citizens :The Moderating Role of Information and Entertainment Needs in the Use of Weibo , CYBERPSYCHOLOGY, BEHAVIOR, AND SOCIAL NETWORKING Volume 15, Number 7, 2012.

25.Mohammed Turki Al-Sudairi , Sino-Saudi Relations: An Economic History, GRC GULF PAPERS ,2012.

26. Mona Al-Haddad, A Reading in the History of Arab-Chinese Relations and Ways to Enhance them, Conference on Prospects 
for Arab-African-Chinese Cooperation within the Framework of the Belt and Road Initiative / Global Africa University - Center for African Research and Studies and the Association of ArabChinese Friendship Societies, Khartoum, 2017, p. 107.

27.OECD (Organisation for Economic Co-operation and Development), Education in China A SNAPSHOT , Paris ,2016 . 28.Osamu Sayama, China's Approach to Soft Power Seeking a Balance between Nationalism, Legitimacy and International Influence, Royal United Services Institute for Defence and Security Studies, 2016.

29.Romana Osman, China's soft power: an assessment of positive image building in the Middle East, the requirements for the degree of Master of Arts in International Relations Leiden University, 2017.

30.Ross Garnaut، \& et all, CHINA'S 40 YEARS OF REFORM AND DEVELOPMENT ,1978 - 2018, Published by ANU Press ,The Australian National University ,Acton ACT 2601, Australia , 2018.

31.Salah Bassiouni Raslan, Confucius, Pioneer of Human Thought, Bibliotheca Alexandrina, 1998.

32.Samira Naim Abdel-Reda, Arab-Chinese Relations, Political and International Review, Issue 23, 2013.

33.Sebastian Hornschild , China in the Middle East: not just about oil ,European Union Institute for Security Studies (EUISS )2016.

34. Shaun Breslin, The Soft Notion of China's 'Soft Power' , Asia Programme Paper : ASP, Chatam house- London, 2011.

35.Sheng Ding ,Chinese Soft Power and Public Diplomacy: An Analysis of China's New Diaspora Engagement Policies in the Xi Era, EAI Fellows Program Working Paper Series No. 43 ,Copyright $\left({ }^{\circ}\right.$ by EAI, 2014 .

36.Sook-Jong Lee, China's Soft Power: Its Limits and Potentials, EAI journal ,Issue Briefing No. 7 , 2009

37.Tony Tai \& et all, Swords into ploughshares? China's Soft Power strategy in Southeast Asia and its challenges 57 (special edition): Revista Brasileira de Política Internacional , 2014.

38.Xin Li \& Verner Worm, Building China's Soft Power for a Peaceful Rise , Published online: , Journal of Chinese Political Science/Association of Chinese Political Studies , 2010. 
39.Xuming QIAN \& Jonathan FULTON, China-Gulf Economic Relationship under the "Belt and Road" Initiative, Asian Journal of Middle Eastern and Islamic Studies, Vol. 11, No. 3 , 2017.

40.Xuming QIAN \& Jonathan FULTON, optc, p14.LINA BENABDALLAH, CHINA'S RELATIONS WITH AFRICA AND THE ARAB WORLD: SHARED TRENDS, DIFFERENT PRIORITIES, South African institute of international affairs, 2018,p6.

41.YIWEI WANG, Public Diplomacy and the Rise of Chinese Soft Power, THE ANNALS OF THE AMERICAN ACADEMY, 2008.

42.Zainab Abdullah, Chinese foreign policy towards the Arab Gulf states (Saudi Arabia as a model), Journal of Political Trends, Arab Democratic Center, Berlin - Germany, Fifth Issue, August 2018, p. $51 .$.

43.Zha Daojiong \& Michal Meidan, China and the Middle East in a New Energy Landscape , The Royal Institute of International Affairs ,Chatham House, 10 St James's Square, London ,2015. 